\title{
Determination of mass transfer coefficients in high-pressure two-phase flows in capillaries using Raman spectroscopy
}

\author{
T. Deleau ${ }^{\mathrm{a}, \mathrm{b}}$, M.H.H. Fechter ${ }^{\mathrm{c}}$, J-J. Letourneau ${ }^{\mathrm{a}}$, S. Camy ${ }^{\mathrm{b}}$, J. Aubin ${ }^{\mathrm{b}, *}$, A.S. Braeuer ${ }^{\mathrm{c}}$, F. Espitalier ${ }^{\mathrm{a}}$ \\ ${ }^{a}$ Université de Toulouse, Mines Albi, Centre RAPSODEE UMR CNRS 5302, Campus Jarlard, Albi, France \\ ${ }^{\mathrm{b}}$ Université de Toulouse, Laboratoire de Génie Chimique, UMR CNRS 5503, INPT, Toulouse, France \\ 'Institute of Thermal, Environmental, and Resources' Process Engineering (ITUN), Technische Universität Bergakademie Freiberg (TUBAF), Leipziger Strasse 28, 09599 \\ Freiberg, Germany
}

\section{H I G H L I G H T S}

- Mass transfer of $\mathrm{CO}_{2}$ into a $\mathrm{H}_{2} \mathrm{O}$-rich phase at high pressure in a capillary is studied.

- A method for the determination of volumetric mass transfer coefficient is presented.

- A thermodynamic model and Raman spectroscopy are coupled to obtain $\mathrm{CO}_{2}$ concentrations.

- The influence of flow rates on the volumetric mass transfer coefficient is studied.

- The mass transfer coefficient varies along the length of the micro-capillary tube.

Keywords:

Mass transfer

High pressure

Microfluidics

Two phase flow

Raman spectroscopy

\section{A B S T R A C T}

This study presents a method for the experimental determination of local volumetric mass transfer coefficients $k_{L} a_{L}$ in a high-pressure two-phase flow of water $\left(\mathrm{H}_{2} \mathrm{O}\right)$ and carbon dioxide $\left(\mathrm{CO}_{2}\right)$ in a microcapillary using Raman spectroscopy. $\mathrm{H}_{2} \mathrm{O}$ and $\mathrm{CO}_{2}$ are continuously and co-currently fed at high pressure $(8,9$ and $10 \mathrm{MPa})$ and moderate temperature $(303 \mathrm{~K})$ into a fused silica micro-capillary. A segmented two-phase flow is obtained therein and the fraction of $\mathrm{CO}_{2}$ in the water-rich phase is measured in-situ at different points along the capillary using Raman spectroscopy. A modified Henry's law is used to compute the equilibrium compositions of the water-rich phase at the desired pressure and temperature. A mixture density model is used to convert the fraction of $\mathrm{CO}_{2}$ in the water-rich phase into a $\mathrm{CO}_{2}$ concentration. The volumetric liquid mass transfer coefficient is computed at various axial locations along the capillary, from the contacting zone to the end of the capillary. Experimentally derived $k_{L} a_{L}$ values range between $2.10^{-3}$ and $5.10^{-3} \mathrm{~s}^{-1}$.

\section{Introduction}

There is an increasing number of supercritical fluid (SCF) applications in diverse industries such as food (Perrut and Perrut, 2019; Brunner, 2005; Ben-Nasr and Coenen, 1994; Lehotay, 1997; Kim et al., 1999; Lumia et al., 2007), cosmetics (Temelli, 2009) and biomedical (Masmoudi et al., 2011; Tsai and Wang, 2019). Moreover, new applications are in development in laboratories (Perrut and Perrut, 2018; Knez et al., 2018). This increasing number of

\footnotetext{
* Corresponding author.

E-mail addresses: thomas.deleau@mines-albi.fr (T. Deleau), michael.fechter@tufreiberg.de (M.H.H. Fechter), jean-jacques.letourneau@mines-albi.fr (J-J. Letourneau), severine.camy@ensiacet.fr (S. Camy), joelle.aubin@ensiacet.fr (J. Aubin), andreas.braeuer@tu-freiberg.de (A.S. Braeuer), fabienne.espitalier@mines-albi.fr (F. Espitalier).
}

applications involves new fluid mixtures and therefore knowledge of the physical and thermodynamic mixture properties (e.g. density, viscosity, surface tension, diffusion coefficient, thermodynamic equilibrium compositions) at high pressure and temperature is essential for designing industrial-scale equipment. Many industrial applications involve two-phase systems where the mass transfer behaviour is a key parameter for the performance of the process. Tools that enable mass transfer coefficients to be measured and quantified are therefore required. Conventional techniques for the time-resolved measurement of phase composition in high-pressure vessels, which resist elevated pressure and temperature often require high investment costs, large quantities of product, specific safety precautions, as well as cumbersome experimental campaigns. These disadvantages can be largely overcome by the use of microfluidic systems. Indeed, the small 


\section{Nomenclature}

A area of Raman peak, $m^{2}$

a $\quad$ specific surface area, $m^{-1}$

C concentration, $\mathrm{mol} / \mathrm{m}^{3}$

$f$ fugacity, $\mathrm{Pa}$

$G \quad$ optical magnification

$H \quad$ Henry's law constant, $P a$

D diameter, $m$

$K \quad$ overall mass transfer coefficient, $\mathrm{m} / \mathrm{s}$

$k \quad$ local mass transfer coefficient, $\mathrm{m} / \mathrm{s}$

$L \quad$ length, $m$

$N \quad$ molar density flux, $\mathrm{mol} / \mathrm{m}^{2} / \mathrm{s}$

$n$ number of moles, $\mathrm{mol}$

pressure, $\mathrm{Pa}$

$R \quad$ ideal gas constant, $J / \mathrm{mol} / \mathrm{K}$

Re Reynolds number $\frac{U D \rho}{\mu}$

$r \quad$ molar ratio in the liquid phase

capillary cross section, $m^{2}$

$T$ temperature, $K$

$U \quad$ velocity, $m / s$

$V \quad$ volume,$m^{3}$

$\dot{V} \quad$ volumetric flow rate, $\mathrm{m}^{3} / \mathrm{s}$

$v$ partial molar volume, $\mathrm{m}^{3} / \mathrm{mol}$

$w \quad$ mass fraction

$x \quad$ mole fraction

$z \quad$ position in the capillary, $\mathrm{m}$

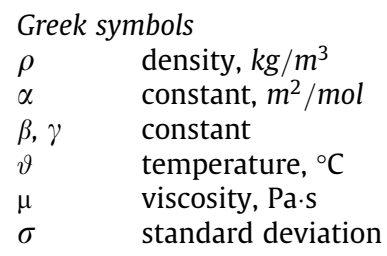

$\begin{array}{ll}\text { Subscripts } \\ \text { cap } & \text { capillary } \\ \mathrm{CO}_{2} & \text { carbon dioxide } \\ \mathrm{F} & \text { fluid } \\ \mathrm{H}_{2} \mathrm{O} & \text { water } \\ \mathrm{L} & \text { liquid } \\ \mathrm{m} & \text { molar } \\ \mathrm{S} & \text { liquid slug } \\ \mathrm{TP} & \text { two-phase }\end{array}$

\section{Superscripts}

a apparent

$\infty \quad$ at infinite dilution

* at equilibrium

- pure

$\sim$ mean value characteristic length scale of microfluidic devices, i.e. capillary diameter, enables experimental mass-transfer times to be drastically reduced. This is because the characteristic times for heat and mass transport are proportional to the square of characteristic length, which is ten orders of magnitude smaller in microfluidic systems than in standard pressurized vessels. This then results in characteristic experimental times - on the order of a few minutes - in microsystems compared with hours in conventional systems. Moreover, small quantities of products are used due to the reduced volume of microfluidic devices, thereby limiting operating costs and increasing safety when using toxic compounds. Risks related to high-pressure operation are also reduced. Microfluidic devices made with capillary tubes are also inexpensive compared with conventional high-pressure cells. Several types of microfluidic systems for high-pressure applications have been developed (Marre et al., 2010), including those using micro-capillary tubes (Macedo Portela da Silva et al., 2014) and polymers (Martin et al., 2016), both of which are fast and inexpensive to make.

Multiphase flow in microfluidic systems has largely been described in the literature, highlighting the enhancement of mass and heat transfer rates and the possibility for process intensification (Peters et al., 2017; Luther et al., 2013). Segmented flow, such as Taylor flow, is mainly studied due to its specific characteristics: quasi homogeneous mixing in both phases and a highly regular flow pattern with large interfacial area. Several experimental methods have been proposed to determine volumetric mass transfer coefficients in gas-liquid flow or liquid-liquid flow at atmospheric pressure and ambient temperature and are classified into two types: online methods and global methods. Online methods include optical techniques that enable the measurement of bubble or drop volumes where the bubble/drop shrinkage is linked to mass transfer rates (Tan et al., 2012; Lefortier et al., 2012; Yao et al., 2014, Zhang et al., 2018), as well as colorimetric (Dietrich et al., 2013) and laser induced fluorescence methods (Kuhn and Jensen, 2012) where concentration data in the liquid phase are obtained. Global methods consist in determining mass transfer coefficients by measuring a solute concentration in both phases at the system inlet and outlet (Irandoust et al., 1992; Bercic and Pintar, 1997; Heiszwolf et al., 2001; Yue et al., 2009; Vandu et al., 2005; Ren et al., 2012) or by pressure drop measurements, which link the pressure drop to the mass transfer coefficient (Yue et al., 2007; Ganapathy et al., 2014; Yao et al., 2017). Global methods allow the determination of average mass transfer coefficients over the length of the microsystem, whereas online methods enable the measurement of values of the mass transfer coefficient at different positions along the microsystem. Data from these experimental studies at atmospheric pressure and ambient temperature have been used to validate mass transfer models and to develop dimensionless correlations (van Baten and Krishna, 2004; Liu and Wang, 2011; Eskin and Mostowfi, 2012). Most mass transfer models in the literature are based on the 'unit-cell model' for segmented flow and the theory of the unit-cell model will be given below.

The objective of this paper is to present a new method for the determination of local mass transfer coefficients in high-pressure two-phase flows in micro-channels using a Raman spectroscopy technique (Klima and Braeuer, 2019), which allows measurement of the molar fraction of $\mathrm{CO}_{2}$ dissolved in the water-rich phase in segmented flow at elevated pressure without sampling. The proposed new method does not rely on as many hypotheses as there are fixed in the unit cell model and thus features a more general applicability. The novelty of the presented method is the combination of these measurements with a thermodynamic model and a specific density mixture model, which are used to firstly compute the concentration of $\mathrm{CO}_{2}$ in the water-rich phase and to secondly compute local values of the mass transfer coefficient along the capillary tube, downstream from the contacting zone. The following sections describe the experimental setup and Raman spectroscopy technique, as well as the models and the calculation of dissolved fluid concentration and mass transfer coefficients. For the sake of 
simplicity, the $\mathrm{CO}_{2}$-rich phase is called the "fluid" phase since this phase can be either liquid or gas depending on the operating conditions. The $\mathrm{H}_{2} \mathrm{O}$-rich phase is called the liquid phase. Finally, a demonstration of the method to determine mass transfer coefficients in $\mathrm{CO}_{2}-\mathrm{H}_{2} \mathrm{O}$ flows at 8,9 and $10 \mathrm{MPa}$ and moderate temperature $303 \mathrm{~K}$ is provided.

\section{Experimental setup}

Fig. 1 shows the experimental setup used to measure the molar fraction of $\mathrm{CO}_{2}$ dissolved in the water-rich phase. It is composed of a capillary tube (60 $\mathrm{cm}$ in length) with a T-junction inlet and highpressure pumps.

The capillaries used in the setup were purchased from Polymicro Technologies. Two sizes of capillary tubes made of silica with a polyimide coating are used for a coaxial injection, where a smaller diameter tube, guiding the $\mathrm{CO}_{2}$, is inserted in a larger diameter tube, guiding the water, as shown in the inset of Fig. 1. The dimensions are listed in Table 1 . These capillary tubes can withstand pressure and temperature up to $25 \mathrm{MPa}$ at $700 \mathrm{~K}$ (Proctor et al., 1967). The connections between the silica capillaries and the other parts of the setup, which is composed of $1 / 16$ in. stainless steel tubing, are made by assembling polymer sleeves, ferules, a stainless-steel T-junction and a simple union.

The fluids used are distilled $\mathrm{H}_{2} \mathrm{O}$ (Standard DIN 43530) and $\mathrm{CO}_{2}<99.5 \%$ in mole. Note that the $\mathrm{H}_{2} \mathrm{O}$ is re-boiled before it is fed to the pump in order to reduce the amount of potentially dissolved compounds. Three Teledyne ISCO pumps are used to feed the fluids through the system. A 260D ISCO pump (capacity of $266 \mathrm{~mL}$, a flow range of $0.001-107 \mathrm{~mL} / \mathrm{min}$, a flow accuracy of $0.5 \%$ of the set point, a pressure accuracy of $0.5 \%$ of the full scale and a max pressure of $51.7 \mathrm{MPa}$ ) feeds the $\mathrm{H}_{2} \mathrm{O}$. A 1000D ISCO pump (capacity of $1015 \mathrm{~mL}$, a flow range of 0.001 to $408 \mathrm{~mL} /$ min, a flow accuracy of $0.5 \%$ of the set point, a pressure accuracy of $0.5 \%$ of the full scale and a max pressure of $13.4 \mathrm{MPa}$ ) feeds $\mathrm{CO}_{2}$; this pump reservoir is cooled down to $278 \mathrm{~K}$ by circulating a temperature conditioning fluid from a conditioning system (F12-Julabo) through its double wall jacket. This measure ensures that the $\mathrm{CO}_{2}$ is in the liquid state inside the syringe pump. Another 260D ISCO pump is placed at the end of the capillary setup in order to maintain the pressure in the system and to take up the mixture. The two feed pumps work in direct volumetric flow-rate-mode and the third pump at the outlet works in reverse volumetric flow rate mode. The flow rate of the reverse pump is calculated in order to maintain constant pressure in the system. All the pumps are equipped with a pressure gauge. 1/16 in. stainless steel pipes are used to connect the pumps to the silica capillary tubes. The lengths of the piping system is short enough to neglect pressure drop, which is not greater than $0.05 \mathrm{MPa}$ over the whole system between the feed pumps and the up-taking pump. The capillary tube is placed in a copper temperature conditioning block (30 cm long), which is heated with four electrical resistance heating rods. The temperature is measured with 5 thermocouples (K-type), which are in contact with the silica capillary tube through dedicated holes. The block is temperature-controlled with a precision of $\pm 0.5 \mathrm{~K}$, which corresponds to the difference between the mean value and the extrema values obtained by the 5 thermocouples during the experiment. The coaxial contacting zone is placed $2.5 \mathrm{~cm}$ within the heating block to ensure the contact of $\mathrm{H}_{2} \mathrm{O}$ and $\mathrm{CO}_{2}$ at the desired pressure and temperature. The assumption that $2.5 \mathrm{~cm}$ is long enough was verified with a computational fluid dynamic simulation. Ten holes are drilled in the temperature conditioning block at $1.25,2.5,3.75,5,6.25,7.5,8.75,10,12.5$ and $17.5 \mathrm{~cm}$ from the contacting zone. The total investigable two-phase flow section is then $17.5 \mathrm{~cm}$ long. The brownish polymer coating of the silica capillary was removed at these spots in order to make the capillary accessible for Raman spectroscopy measurements.

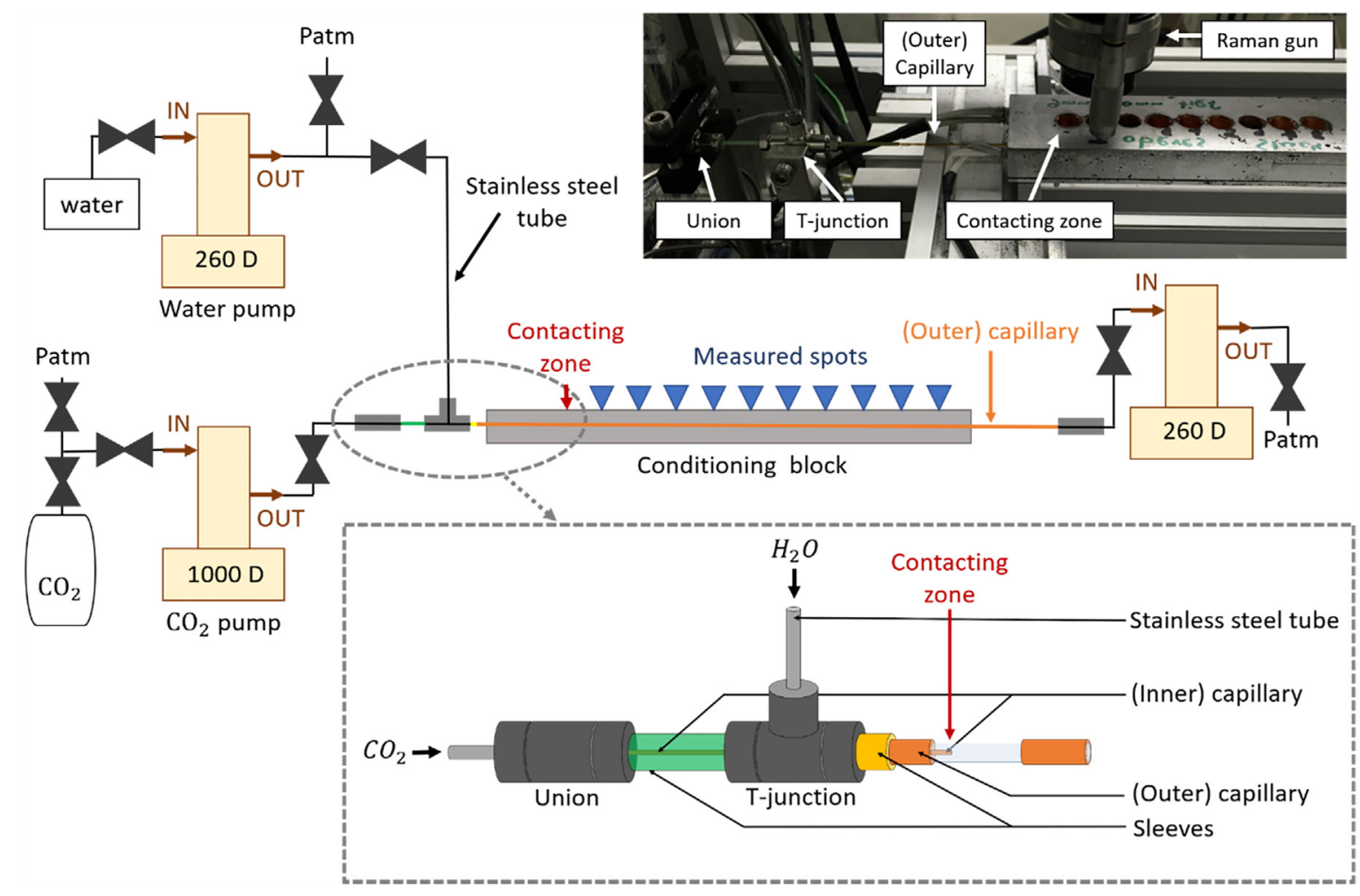

Fig. 1. Schematic diagram and picture of the experimental setup used to determine mass transfer coefficients in high-pressure two-phase flows 
Table 1

Dimensions of the capillary tubes used $(\mu \mathrm{m})$. ID = inner diameter, OD = outer diameter.

\begin{tabular}{|c|c|c|c|c|}
\hline & $\min I D$ & $\max$ ID & $\min O D$ & $\max$ OD \\
\hline Inner capillary & 74.9 & 75.3 & 151.3 & 151.5 \\
\hline Outer capillary & 296.6 & 296.8 & 792.3 & 794.2 \\
\hline
\end{tabular}

\section{Unit-cell model}

Fig. 2 depicts a unit cell for segmented fluid-liquid flow. The unit cell comprises one element of the dispersed fluid phase (called from now on "bubble" for the sake of simplicity), the liquid film surrounding it and one liquid slug. As can be seen in the lower part of Fig. 2, the unit cell model simplifies the segmented flow pattern based on a certain number of assumptions, which will be described below.

According to the double resistance diffusion model, which is given in Fig. 3, the molar flux of $\mathrm{CO}_{2}$ can be written considering the continuity of flux at the interface

$\dot{N}_{\mathrm{CO}_{2}}=k_{L}^{m}\left(x_{\mathrm{CO}_{2}, i}-x_{\mathrm{CO}_{2}}\right)=K_{L}^{m}\left(x_{\mathrm{CO}_{2}}^{*}-x_{\mathrm{CO}_{2}}\right)$

where the lowercase $k_{L}^{m}$ is the liquid local mass transfer coefficient $\left(\mathrm{mol} \cdot \mathrm{m}^{-2} \cdot \mathrm{s}^{-1}\right)$ and the capital letter $K_{L}^{m}$ the liquid global mass transfer coefficient $\left(\mathrm{mol} \cdot \mathrm{m}^{-2} \cdot \mathrm{s}^{-1}\right)$.

The main hypotheses of the unit cell model are the following:

- There is no mass transfer between two consecutive unit cells, the overall amount of substance in one unit cell is constant. (H1)

- The fluid and liquid are in equilibrium at the interface, the twofilm model is applied. (H2)

- Mass transfer occurs from the fluid phase to liquid phase only (Fig. 3(b)) (H3), which implies that $k_{L}^{m}=K_{L}^{m}$ (because the mass transport resistance in the fluid phase is approximated zero) and then $x_{\mathrm{CO}_{2}}^{*}=x_{\mathrm{CO}_{2}, i}$. This assumption is only valid when the fluid compound is soluble in the liquid phase and the compound in the liquid phase is not or slightly soluble in the fluid phase. This is the case in this study where the amount of $\mathrm{H}_{2} \mathrm{O}$ soluble in the $\mathrm{CO}_{2}$-rich phase is negligible compared with the solubility of $\mathrm{CO}_{2}$ in the $\mathrm{H}_{2} \mathrm{O}$-rich phase. Consequently, only the migration of $\mathrm{CO}_{2}$ from the $\mathrm{CO}_{2}$-rich phase to the $\mathrm{H}_{2} \mathrm{O}$-rich phase has an effect on the concentration of $\mathrm{CO}_{2}$ in the $\mathrm{H}_{2} \mathrm{O}$-rich phase.

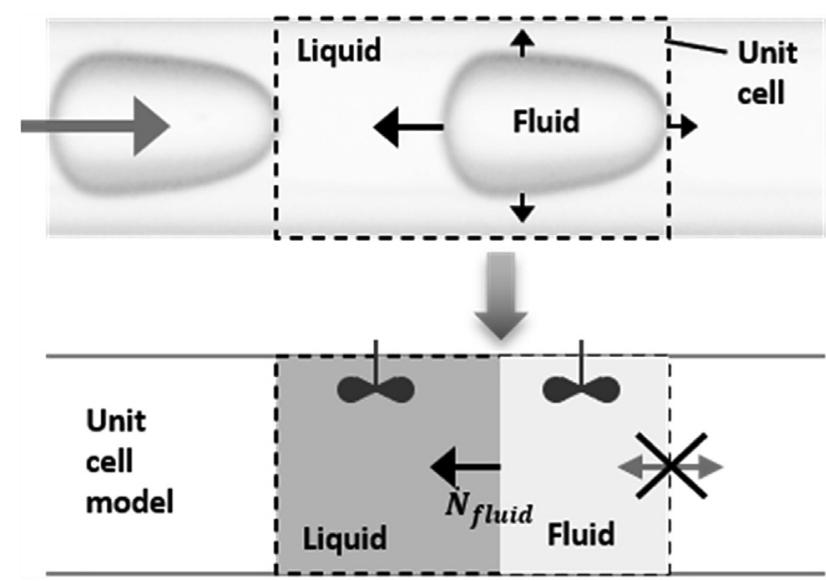

Fig. 2. Unit cell model of fluid-liquid segmented flow where $\dot{N}_{\text {fluid }}$ is the molar density flux of fluid in $\mathrm{mol} \cdot \mathrm{m}^{-2} \cdot \mathrm{s}^{-1}$.
- Fluid and liquid phases are perfectly mixed (H4), i.e. the phases are considered as homogeneous and described by average bulk fractions $x$ and $y$ are taken. Therefore, the greyish gradients in Fig. 3 can be represented by straight horizontal dashed black lines. There is no liquid film surrounding the bubble (film separating the bubble from the inner wall), the camera observation showed that the bubble occupies almost the entire cross section of the capillary tube and that the liquid film is negligible in the current conditions). Therefore both the bubbles and liquid slugs are assumed to have the same velocity (H5). This velocity is equal to the velocity of the two-phase flow at the inlet $U_{T P}=\frac{\dot{V}_{\mathrm{CO}_{2}}+\dot{V}_{\mathrm{H}_{2} \mathrm{O}}}{\mathrm{S}}=\frac{\mathrm{dz}}{\mathrm{dt}}$ where $\dot{V}_{\mathrm{CO}_{2}}$ and $\dot{V}_{\mathrm{H}_{2} \mathrm{O}}$ are the volumetric flow rates of the fluid and liquid phases at conditions prevailing inside the capillary, $S$ is the inner cross section of the capillary tube and $z$ is the length along the capillary from the contacting zone of $\mathrm{H}_{2} \mathrm{O}$ and $\mathrm{CO}_{2}$. This velocity allows the transformation from the temporal to the spatial scale.

Following these hypotheses, the evolution of the concentration of $\mathrm{CO}_{2}$ in the $\mathrm{H}_{2} \mathrm{O}$-rich phase as a function of the distance downstream of the contacting point $z=0$ can be derived:

$\frac{d C_{\mathrm{CO}_{2}}}{d z}=\frac{k_{L} a_{L}}{U_{T P}}\left(C_{\mathrm{CO}_{2}}^{*}-C_{\mathrm{CO}_{2}}(z)\right)$

where $k_{L}$ is the liquid local mass transfer coefficient $\left(\mathrm{m} . \mathrm{s}^{-1}\right), a_{L}$ is the specific surface (equal to the ratio of the area available for mass transfer over the volume of the liquid slug), $\mathrm{C}_{\mathrm{CO}_{2}}(\mathrm{z})$ is the concentration of $\mathrm{CO}_{2}$ in the liquid slug $\left(\mathrm{mol} . \mathrm{m}^{-3}\right)$ at a certain distance $\mathrm{z}$ downstream of the contacting location and $\mathrm{C}_{\mathrm{CO}_{2}}^{*}$-is the concentration of $\mathrm{CO}_{2}$ in the liquid slug in thermodynamic equilibrium with the $\mathrm{CO}_{2}$-rich phase.

- A final assumption commonly used is that the volumetric mass transfer coefficient $k_{L} a_{L}$ is constant along the length of the capillary tube (or microchannel) (H6). This assumption is used when the mass transfer coefficient is determined by global methods based on inlet and outlet concentration measurements.

If $k_{L} a_{L}$ is constant, Eq. (2) can be integrated:

$\left.k_{\mathrm{L}} a_{\mathrm{L}}=\frac{U_{\mathrm{TP}}}{z} \ln \frac{\mathrm{C}_{\mathrm{CO}_{2}}^{*}-C_{\mathrm{CO}_{2}}(z=0)}{C_{\mathrm{CO}_{2}}^{*}-C_{\mathrm{CO}_{2}}(z)}\right)$

Eq. (3) is used for the determination of the volumetric mass transfer coefficients using global measurement methods where the concentration of the $\mathrm{CO}_{2}$ dissolved in the liquid phase is measured at the outlet of the system. At ambient pressure and for gases, it is also possible to correlate the bubble dimension with the mass transfer coefficient using the ideal gas law. This technique then allows to compute mass transfer coefficient to be calculated from images of bubble/drop sizes.

Most of the conventional methods at ambient conditions are based on the previous hypothesis. When operating at highpressure, however, the conventional experimental methods, models and assumptions, which have been developed for ambient conditions, are no longer well suited. This is due to a number of 


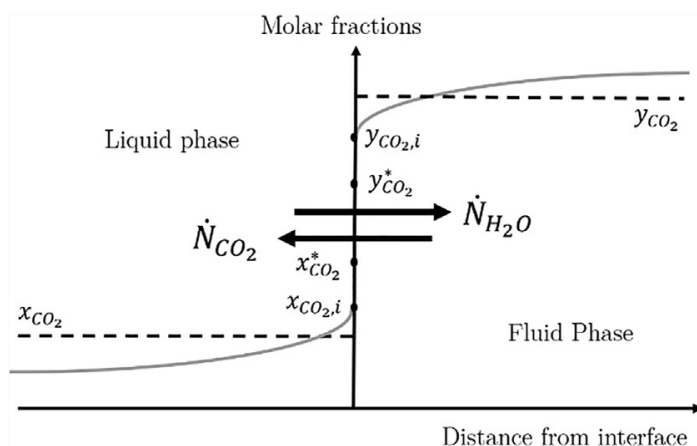

(a)

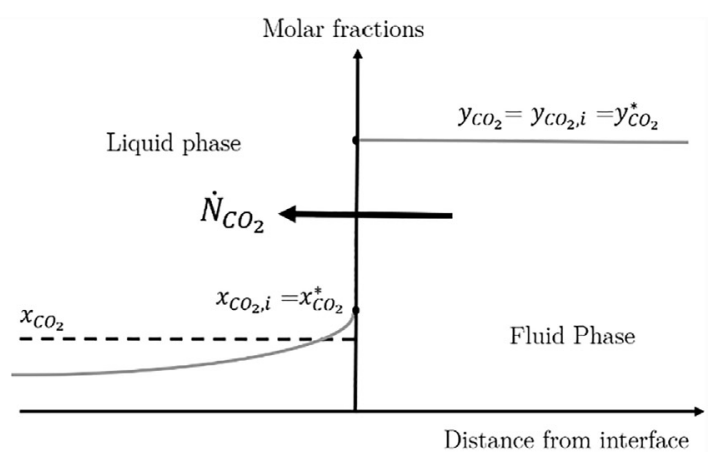

(b)

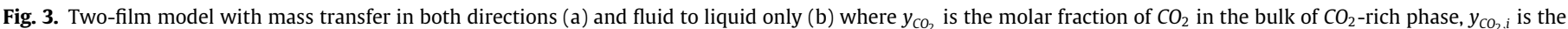

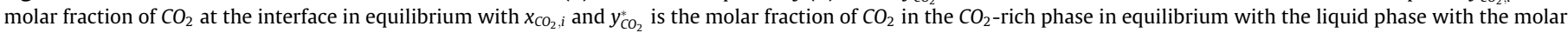
fraction of $\mathrm{CO}_{2}$ in the bulk, $x_{\mathrm{CO}_{2}}$. Adapted from (Bird, 2002).

reasons. Under elevated pressure the behaviour of many gases cannot be described by the ideal gas law; this is particularly the case for $\mathrm{CO}_{2}$. As a result, a thermodynamic model is required in order to link the bubble volume and the number of moles in the fluid phase. Furthermore, the physical properties, such as density and viscosity, of the liquid phase and the fluid phase can change along the length of the microchannel because they are highly dependent on the amount of compounds dissolved in the liquid or the fluid phase. Taking samples of each of the phases at the outlet of the system is also difficult since the system is operating under highpressure and also since undesired mass transfer between the fluid and liquid phases may occur in basic fluid-liquid separators. For these reasons, it is often very difficult to link a change in bubble volume to mass transfer rates in high-pressure systems and the application of existing correlations for mass transfer coefficients are not well adapted since they also are based on the simplifying hypothesis (H1-H6).

\subsection{Operating conditions}

The operating pressures studied are 8,9 and $10 \mathrm{MPa}$ at a temperature of $303 \mathrm{~K}$. The ISCO pumps are set to deliver a constant volumetric flow rate. However, since there is a temperature change and therefore a density change of the fluids - between the pumps and the capillary tube, the volumetric flow rates in the capillary tube must be recalculated to take into account the change in density. The volumetric flow rates in the capillary tube range from $50 \mu \mathrm{L} / \mathrm{min}$ to $200 \mu \mathrm{L} / \mathrm{min}$ for $\mathrm{H}_{2} \mathrm{O}\left(\operatorname{Re}_{L}=\rho_{L} U_{L} D / \mu_{L}=4-22\right)$ and from $37 \mu \mathrm{L} / \mathrm{min}$ to $108 \mu \mathrm{L} / \mathrm{min}$ for $\mathrm{CO}_{2}\left(R e_{F}=\rho_{F} U_{F} D / \mu_{F}=11-96\right)$. These flow rates lead to residence times of the order of one second. Note that all the volumetric flow rates in this paper are given at the temperature and pressure of the microfluidic system. These flow rate ranges have been chosen such that there is a $\mathrm{CO}_{2}-\mathrm{H}_{2} \mathrm{O}$ flow with a concentration gradient of $\mathrm{CO}_{2}$ in the $\mathrm{H}_{2} \mathrm{O}$-rich phase along the length of the capillary tube and that the $\mathrm{H}_{2} \mathrm{O}$-rich phase is not saturated with the $\mathrm{CO}_{2}$ at the final measurement point, i.e. at $z=175 \mathrm{~mm}$. The $\mathrm{CO}_{2}$ to $\mathrm{H}_{2} \mathrm{O}$ ratio at the inlet is then varied in order to obtain thermodynamic equilibrium (i.e. where the $\mathrm{H}_{2} \mathrm{O}$ rich phase is saturated by $\mathrm{CO}_{2}$ ) at several measurement points For each combination of pressure and temperature, the influence of the volumetric flow rate of one phase has been studied, whilst the volumetric flow rate of the other phase was kept constant.

\section{Raman spectra measurements}

The Raman spectroscopy setup given in Fig. 4 is that developed by Klima and Braeuer (2019). This setup has previously been used to obtain thermodynamic equilibrium data of two-phase fuelnitrogen systems under engine-like conditions (i.e. at high pressure and high temperature). In particular, the setup enables Raman spectra to be measured in one of the fluids of a fast moving segmented two-phase flow (the measurement is possible in both phases). A Cobolt Samba $532 \mathrm{~nm}$ laser (green, operated with $150 \mathrm{~mW}$ ) is connected to a Raman gun (Braeuer-engineering) with an optical fiber and is focused in the capillary tube at the measurement point. The inelastic Raman signal (red shifted) is collected in back-scattering mode passing through a dichroic mirror and a long-pass filter where the elastic signal, which corresponds to the laser excitation wavelength is separated. The inelastic Raman signal is then focused into an optical fiber that goes to a fiber switch and then to a spectrometer (Ocean Optics QEpro), which receives the signal. In parallel, a photodiode is aligned with the laser beam under the capillary tube in order to receive the signal from the laser beam transmitted through the capillary. When a bubble is passing through the capillary at the measurement point, the laser bends and alters the intensity signal received by the photodiode. This intensity signal is recorded on an oscilloscope and corresponds to the periodicity of the segmented flow. A pulse generator (Model 9618, Quantum Composers) is used to create an electric signal that is positive during the bump or the crook (corresponding to the $\mathrm{H}_{2} \mathrm{O}$-rich phase or the $\mathrm{CO}_{2}$-rich phase) of the photodiode intensity signal. This electric signal is sent to the fiber switch (PiezoSystem Jena), which has one optical fiber inlet (from the Raman probe) and two outlets (one to the spectrometer and one dead ended). Depending on the electrical signal sent to the fiber switch, the signal from the Raman probe will go to the dead ended outlet or to the spectrometer. This is what allows the signal in either the $\mathrm{H}_{2} \mathrm{O}$-rich phase or the $\mathrm{CO}_{2}$-rich phase to be obtained.

At each measurement point, 16 spectra have been recorded, each with a signal integration time of $3 \mathrm{~s}$. However, the signal arrives in small increments (signal from the $\mathrm{H}_{2} \mathrm{O}$-rich phase only). Nevertheless, the signal integration time is long enough to obtain a clear spectrum. The mean of the 16 spectra is computed for each measurement point, the baseline is removed (using a spline method with the following node points $[650,930,1150,1200$, $1300,1420,1470,1530,1800,2000,2300,2500,2600,2700$, $3850,4000 \mathrm{~cm}^{-1}$ ]) and the spectra are normalized by the $\mathrm{H}_{2} \mathrm{O}$ band in order to visualize and compare the amount of $\mathrm{CO}_{2}$ in the $\mathrm{H}_{2} \mathrm{O}$-rich phase at each point. An example of the spectra obtained at the different measurement points is shown in Fig. 5. The peak between $2700 \mathrm{~cm}^{-1}$ and $3900 \mathrm{~cm}^{-1}$ corresponds to the $\mathrm{H}_{2} \mathrm{O}$ and the Fermi dyad of $\mathrm{CO}_{2}$ is present between $1200 \mathrm{~cm}^{-1}$ and $1450 \mathrm{~cm}^{-1}$. As the distance of the measurement point from the contacting point of $\mathrm{CO}_{2}$ and $\mathrm{H}_{2} \mathrm{O}$ increases, it 


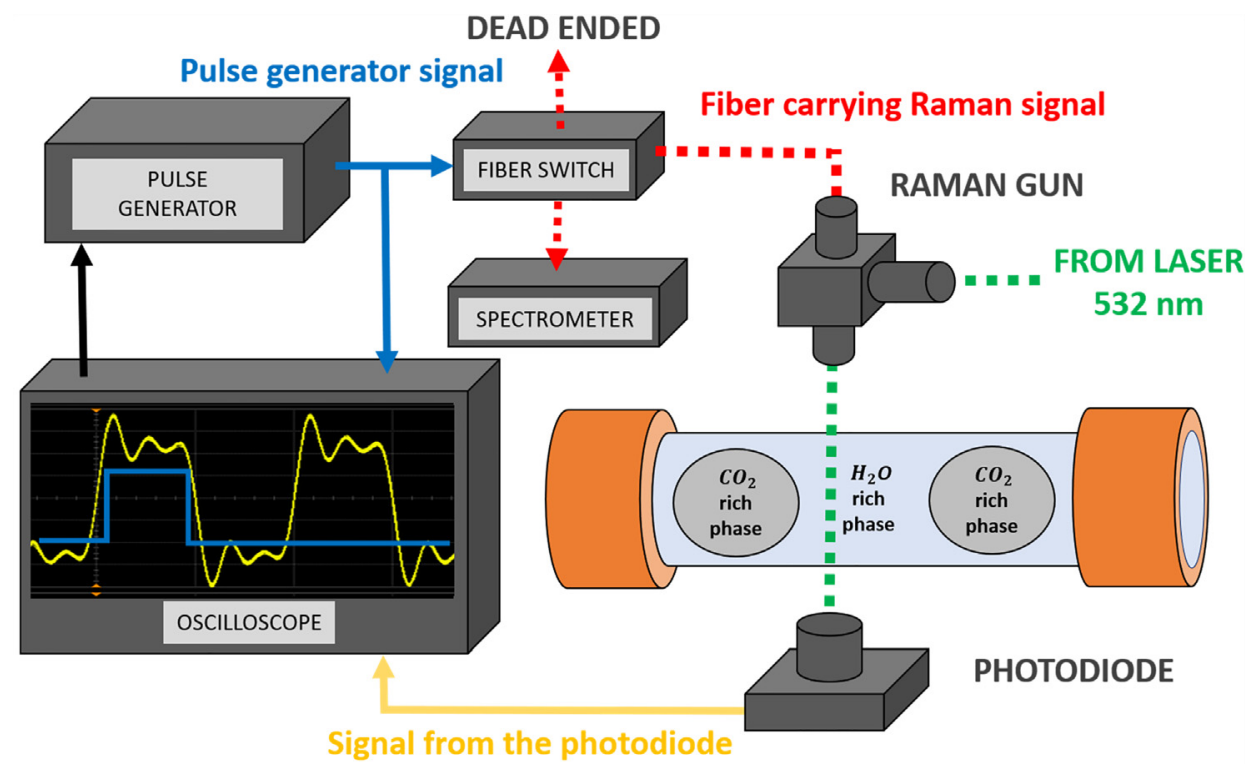

Fig. 4. Schematic diagram of the Raman spectroscopy setup for obtaining spectra in a single phase of a segmented two-phase flow.

can be seen that the signal intensity of the $\mathrm{CO}_{2}$ Fermi dyad increases, which corresponds to a greater amount of $\mathrm{CO}_{2}$ dissolved in the $\mathrm{H}_{2} \mathrm{O}$-rich phase.

\section{Determination of mass transfer}

The novelty of this work is to determine local volumetric mass transfer coefficients $k_{L} a_{L}$ in continuous high-pressure two-phase flows where the physical properties of the fluids vary. In order to do this, the Raman spectroscopy technique described in Section 4 is used to determine the $\mathrm{CO}_{2}$ to $\mathrm{H}_{2} \mathrm{O}$ molar fraction ratio $\frac{x_{\mathrm{CO}_{2}}}{x_{\mathrm{H}_{2} \mathrm{O}}}$ at each measurement point. This ratio is then coupled with the density of the liquid mixture $\rho_{L}$ to compute the concentration of $\mathrm{CO}_{2}$ dissolved in the $\mathrm{H}_{2} \mathrm{O}$-rich phase $\mathrm{C}_{\mathrm{CO}_{2}}$ at each point. Following this, the concentration data is used with the unit cell model to calculate the volumetric mass transfer coefficient $k_{L} a_{L}$ at each position in the capillary tube.

\subsection{Determination of $\mathbf{C}_{\mathrm{Co}_{2}}$}

The dissolution of $\mathrm{CO}_{2}$ into a $\mathrm{H}_{2} \mathrm{O}$-rich phase leads to the presence of $\mathrm{H}_{2} \mathrm{CO}_{3}, \mathrm{HCO}_{3}^{-}, \mathrm{CO}_{3}^{2-}$ and $\mathrm{CO}_{2}$ in aqueous form in the $\mathrm{H}_{2} \mathrm{O}$ rich phase. Nevertheless, in the study of Anderson (1977), it has been shown that in the $\mathrm{H}_{2} \mathrm{O}$-rich phase, the amount of species other than $\mathrm{CO}_{2}$ is negligible at $283 \mathrm{~K}$ and $4.5 \mathrm{MPa}$ and decreases further with an increase in pressure. Therefore, in this work, the total amount of $\mathrm{CO}_{2}$ dissolved in the $\mathrm{H}_{2} \mathrm{O}$-rich phase is considered to be present as dissolved molecular $\mathrm{CO}_{2}$. The concentration of $\mathrm{CO}_{2}$ in the $\mathrm{H}_{2} \mathrm{O}$-rich phase $\mathrm{C}_{\mathrm{CO}_{2}}$ is determined by Eq. (4).

$C_{\mathrm{CO}_{2}}=\frac{\left.\rho_{L\left(T, P, x_{\mathrm{CO}_{2}}\right.}\right)}{M_{\mathrm{CO}_{2}}+\frac{x_{\mathrm{H}_{2 O} \mathrm{O}}}{x_{\mathrm{CO}_{2}}} M_{\mathrm{H}_{2} \mathrm{O}}}$

where $\rho_{L}\left(T, P, x_{\mathrm{CO}_{2}}\right)$ is the liquid density of the $\mathrm{H}_{2} \mathrm{O}$-rich phase, $x_{\mathrm{CO}_{2}}$ is the molar fraction of $\mathrm{CO}_{2}$ and $\mathrm{M}_{\mathrm{CO}_{2}}$ and $\mathrm{M}_{\mathrm{H}_{2} \mathrm{O}}$ are the molar mass of $\mathrm{CO}_{2}$ and $\mathrm{H}_{2} \mathrm{O}$, respectively. The ratio of molar fraction of $\mathrm{CO}_{2}$ to $\mathrm{H}_{2} \mathrm{O}$ is obtained from the Raman spectra and is proportional to

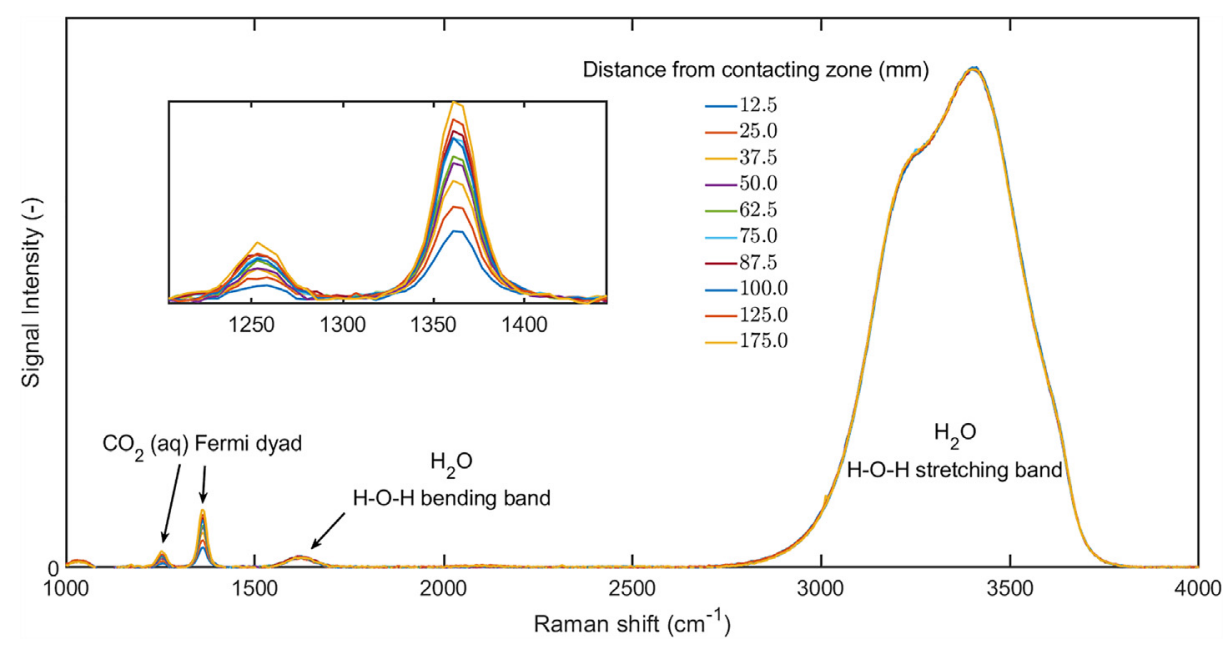

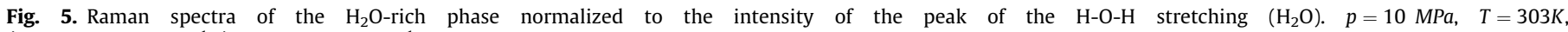
$\dot{\mathrm{V}}_{\mathrm{H}_{2} \mathrm{O}}=110 \mu \mathrm{L} \cdot \mathrm{min}^{-1}, \dot{\mathrm{V}}_{\mathrm{CO}_{2}}=61.5 \mu \mathrm{L} \cdot \mathrm{min}^{-1}$. 
the peak area ratio $\frac{A_{\mathrm{CO}_{2}}}{A_{\mathrm{H}_{2} \mathrm{O}}}$ at each measurement point (where $A_{\mathrm{H}_{2} \mathrm{O}}$ and $A_{\mathrm{CO}_{2}}$ are the areas from the Raman spectra taken between $2700 \mathrm{~cm}^{-1}$ to $3900 \mathrm{~cm}^{-1}$ and $1200 \mathrm{~cm}^{-1}$ to $1450 \mathrm{~cm}^{-1}$ respectively):

$\frac{A_{\mathrm{CO}_{2}}}{A_{\mathrm{H}_{2} \mathrm{O}}}=\alpha \frac{x_{\mathrm{CO}_{2}}}{x_{\mathrm{H}_{2} \mathrm{O}}}$

The proportionality constant $\alpha$ is determined by calculating the $\frac{x_{\mathrm{CO}_{2}}}{x_{\mathrm{H}_{2} \mathrm{O}}}$ ratio at equilibrium with a thermodynamic model for the solubility of $\mathrm{CO}_{2}$ in $\mathrm{H}_{2} \mathrm{O}$-rich phase (as described in Section 5.1.1) for experiments where thermodynamic equilibrium is achieved. $\alpha$ is then used to determine $\frac{x_{\mathrm{CO}_{2}}}{x_{\mathrm{H}_{2} \mathrm{O}}}$ from $\frac{A_{\mathrm{CO}_{2}}}{A_{\mathrm{H}_{2} \mathrm{O}} \mathrm{O}}$ at each measurement point for the other experiments where thermodynamic equilibrium has not been achieved yet. The value $\alpha$ was obtained with 43 equilibrium points. The final value was 0.239 with a standard deviation of $0.007(2.9 \%)$. The deviation obtained here can be drastically reduced with binary systems where the dispersed phase is more soluble in the continuous phase (thereby providing higher resolution of the calibration curve). In the case of $\mathrm{CO}_{2}$ and $\mathrm{H}_{2} \mathrm{O}$, the maximum amount of $\mathrm{CO}_{2}$ in the $\mathrm{H}_{2} \mathrm{O}$-rich phase is $3 \%$ in mass under the conditions presented in this paper. This value is low compared with other systems studied in the literature, such as $\mathrm{CO}_{2}$ and ethanol.

5.1.1. Determination of the equilibrium fraction of $\mathrm{CO}_{2}$ in the $\mathrm{H}_{2} \mathrm{O}$-rich phase, $\boldsymbol{x}_{\mathrm{co}}^{*}$

In this paper, the equilibrium fraction of $\mathrm{CO}_{2}$ in the $\mathrm{H}_{2} \mathrm{O}$-rich phase, $x_{\mathrm{CO}_{2}}^{*}$, is calculated using the work of Enick and Klara (1990) with the exception that the fugacity of $\mathrm{CO}_{2}, f_{\mathrm{CO}_{2}}$, is calculated from the Span and Wagner (1996) equation of state. In the work of Enick and Klara (1990), a Henry's law analysis is used with a Poynting correction, as given in Eq. (6).

$\frac{f_{\mathrm{CO}_{2}}}{x_{\mathrm{CO}_{2}}^{*}}=H_{\mathrm{CO}_{2}}^{*} \exp \left(\frac{v_{\mathrm{CO}_{2}}^{\infty} P}{R T}\right)$

Enick and Klara (1990) compiled 110 solubility data points for a range of temperature from $298 \mathrm{~K}$ to $523 \mathrm{~K}$ and pressure from 3.40 MPa to $72.41 \mathrm{MPa}$, and regressed both the reference Henry's law constant, $\mathrm{H}_{\mathrm{CO}_{2}}^{*}$, and the partial molar volume of $\mathrm{CO}_{2}$ at infinite dilution, $v_{\mathrm{CO}_{2}}^{\infty}$, with Eq. (6) in order to fit with the experimental solubility data. Empirical correlations for each of the parameters are given below in Eqs. (7) and (8).

$$
\begin{aligned}
H_{\mathrm{CO}_{2}}^{*}= & -5032.99+30.74113 T-0.052667 T^{2}+2.630218 \\
& \times 10^{-5} T^{3} \\
v_{\mathrm{CO}_{2}}^{\infty}= & 1799.36-17.8218 T+0.0659297 T^{2}-1.05786 \\
& \times 10^{-4} T^{3}+6.200275 \times 10^{-8} T^{4}
\end{aligned}
$$

where $\mathrm{T}$ is the temperature in Kelvin.

\subsubsection{Determination of the liquid mixture density of the $\mathrm{H}_{2} \mathrm{O}$-rich} phase, $\boldsymbol{\rho}_{\mathbf{L}}$

Mixture densities are computed following the methodology of Bachu and Adams (2003). In the case of non-ideal solutions such as $\mathrm{H}_{2} \mathrm{O}$ and $\mathrm{CO}_{2}$ mixtures, it is assumed that the volume of the liquid mixture is the sum of two contributions: the volume occupied by the solvent in its pure state (i.e. pure $\mathrm{H}_{2} \mathrm{O}$ ) and the apparent volume occupied by the solute (i.e. $\mathrm{CO}_{2}$ ).

The total volume of the solution is then written using the partial molar volume of each component as shown in Equation (9).

$$
\begin{aligned}
V_{L} & =n_{\mathrm{H}_{2} \mathrm{O}}\left(\frac{\partial V}{\partial n_{\mathrm{H}_{2} \mathrm{O}}}\right)_{T, P, n_{\mathrm{CO}_{2}}}+n_{\mathrm{CO}_{2}}\left(\frac{\partial V}{\partial n_{\mathrm{CO}_{2}}}\right)_{T, P, n_{\mathrm{H}_{2} \mathrm{O}}} \\
& =n_{\mathrm{H}_{2} \mathrm{O}} v_{\mathrm{H}_{2} \mathrm{O}}+n_{\mathrm{CO}_{2}} v_{\mathrm{CO}_{2}}
\end{aligned}
$$

The apparent molar volume of $\mathrm{CO}_{2}, v_{\mathrm{CO}_{2}}^{a}$, defined in Equation (10) is the difference between the total volume and the molar volume of pure $\mathrm{H}_{2} \mathrm{O}, v_{\mathrm{H}_{2} \mathrm{O}}^{o}$, multiplied by the number of moles of $\mathrm{H}_{2} \mathrm{O}$ and divided by the number of moles of $\mathrm{CO}_{2}$. The apparent molar volume is different to the partial molar volume, $v_{\mathrm{H}_{2} \mathrm{O}}$, as shown in Equation (11).

$$
v_{\mathrm{CO}_{2}}^{a}=\frac{V_{L}-n_{\mathrm{H}_{2} \mathrm{O}} v_{\mathrm{H}_{2} \mathrm{O}}^{o}}{n_{\mathrm{CO}_{2}}}
$$

$V_{L}=n_{\mathrm{CO}_{2}} v_{\mathrm{CO}_{2}}+n_{\mathrm{H}_{2} \mathrm{O}} v_{\mathrm{H}_{2} \mathrm{O}}=n_{\mathrm{CO}_{2}} v_{\mathrm{CO}_{2}}^{a}+n_{\mathrm{H}_{2} \mathrm{O}} v_{\mathrm{H}_{2} \mathrm{O}}^{o}$

For $\mathrm{CO}_{2}$ and $\mathrm{H}_{2} \mathrm{O}$ mixtures, numerous correlations for $v_{\mathrm{CO}_{2}}^{a}$ can be found in the literature due to their use in geology (Andersen et al., 1992; Enick and Klara, 1990). In this work, the correlation

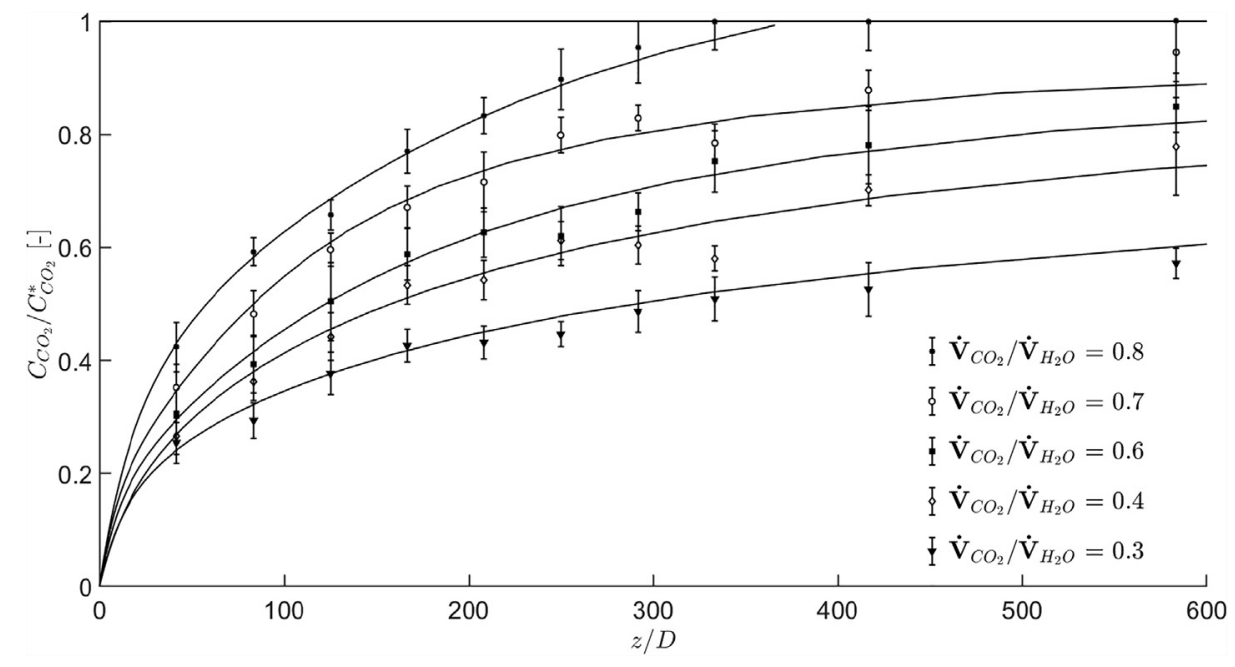

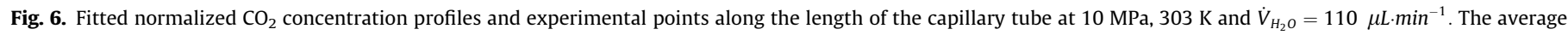
deviation between the fitted concentration profiles and the experimental points are respectively $0.7 \%, 0.5 \%, 0.3 \%, 0.4 \%$ and $0.5 \%$. 


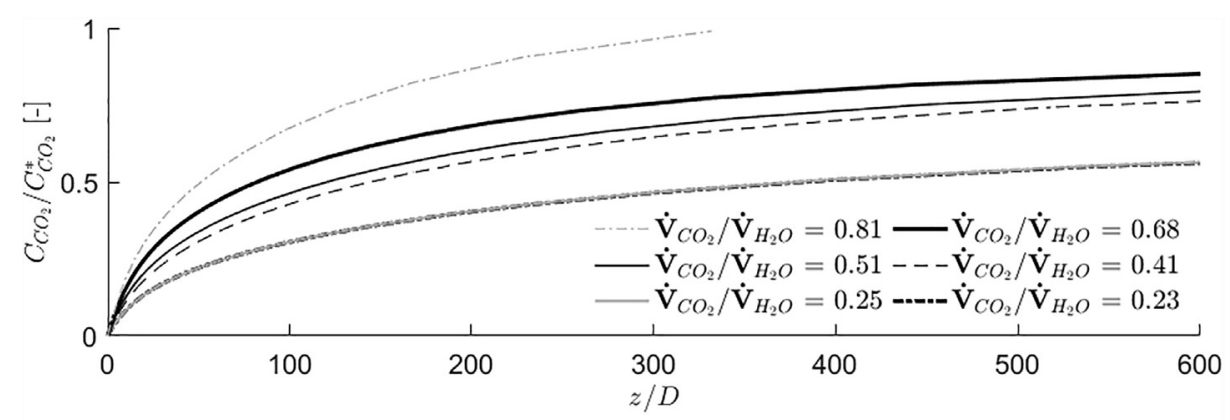

(a)

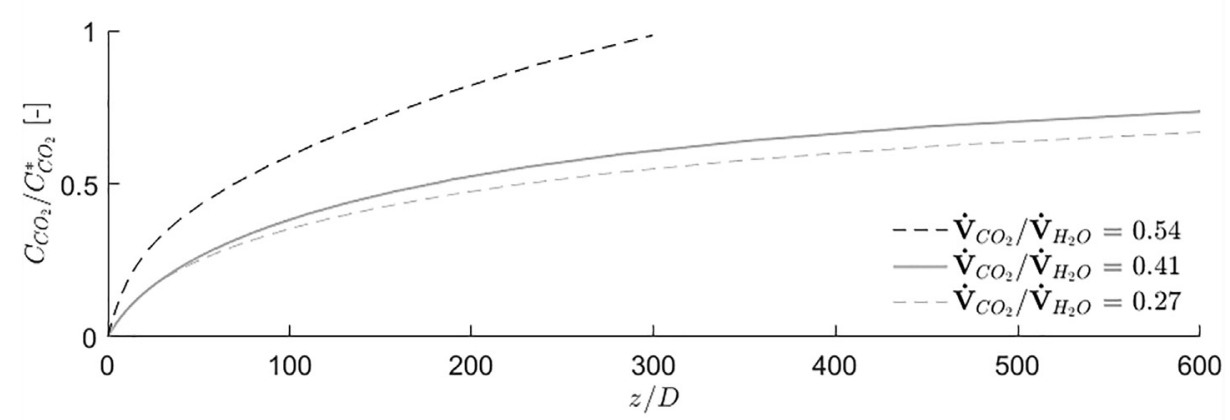

(b)

Fig. 7. Fitted normalized $\mathrm{CO}_{2}$ concentration profiles at $8 \mathrm{MPa} 303 \mathrm{~K}$. (a) $\dot{V}_{\mathrm{CO}_{2}}=40.5 \mu \mathrm{L} \cdot \mathrm{min}^{-1}$ (b) $\dot{V}_{\mathrm{H}_{2} \mathrm{O}}=200 \mu \mathrm{L} \cdot \mathrm{min}^{-1}$.

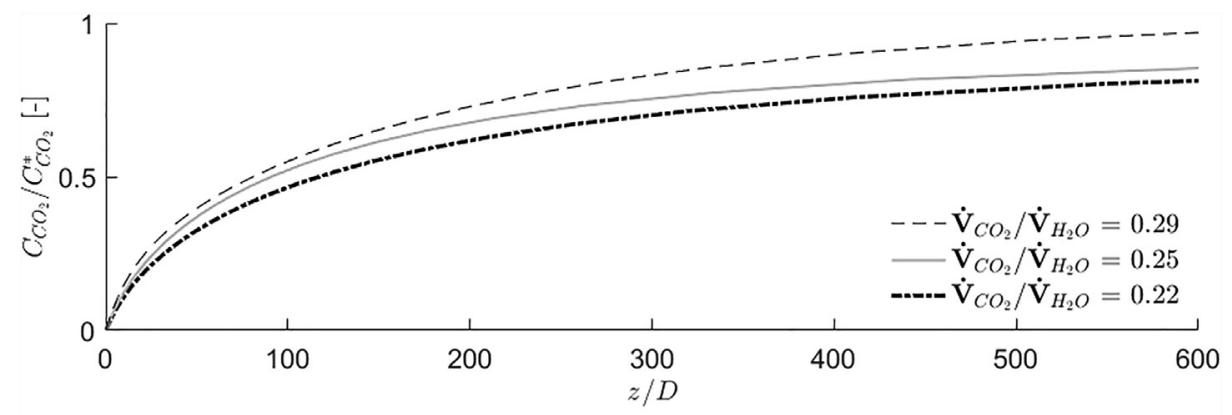

(a)

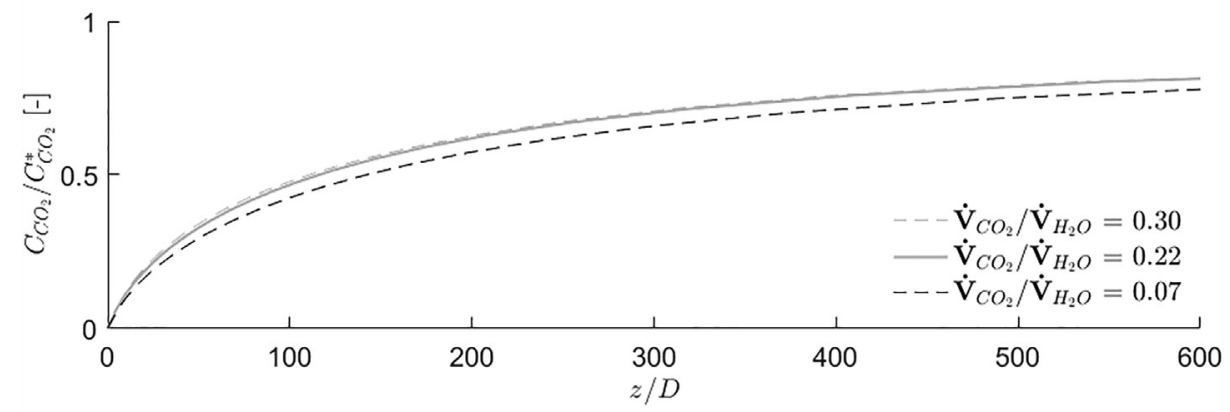

(b)

Fig. 8. Fitted normalized $\mathrm{CO}_{2}$ concentration profiles at $9 \mathrm{MPa} 303 \mathrm{~K}$. (a) $\dot{V}_{\mathrm{CO}_{2}}=38.2 \mu \mathrm{L} \cdot \mathrm{min}^{-1}$ (b) $\dot{V}_{\mathrm{H}_{2} \mathrm{O}}=170 \mu \mathrm{L} \cdot \mathrm{min}^{-1}$.

from Garcia (2001) given by Eq. (12) is employed. It is based on 54 data points obtained for temperature and pressure ranges of $278 \mathrm{~K}$ to $573 \mathrm{~K}$ and $0.2 \mathrm{MPa}$ to $35 \mathrm{MPa}$, respectively.

$$
\begin{aligned}
v_{\mathrm{CO}_{2}}^{a}= & 37.51-9.585 \times 10^{-2} \vartheta+8.740 \times 10^{-4} \vartheta^{2}-5.044 \\
& \times 10^{-7} \vartheta^{3}
\end{aligned}
$$

where $\vartheta$ is temperature in ${ }^{\circ} \mathrm{C}$ and $v_{\mathrm{CO}_{2}}^{a}$ in $\mathrm{cm}^{3} / \mathrm{mol}$. Garcia (2001) demonstrated that the influence of pressure is negligible when the temperature is lower than $573 \mathrm{~K}$, which is the case in the current work.

Eq. (13) gives the liquid density of the $\mathrm{H}_{2} \mathrm{O}$ and $\mathrm{CO}_{2}$ mixture, $\rho_{L}\left(T, P, x_{\mathrm{CO}_{2}}\right)$ derived from Eq. (11): 


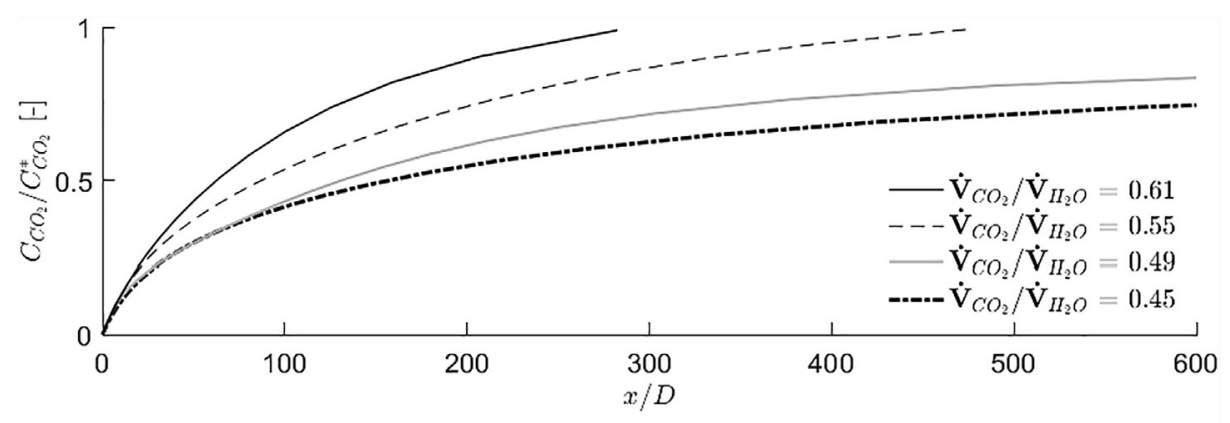

(a)

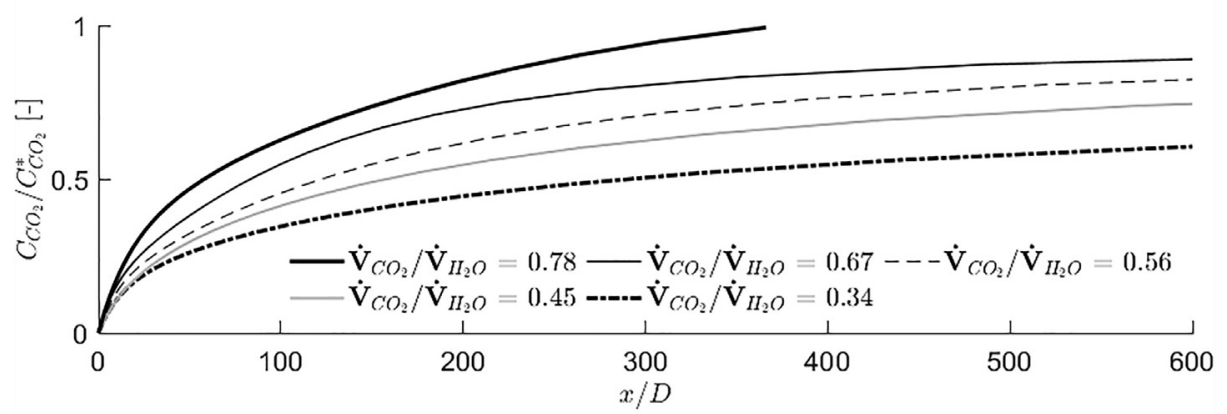

(b)

Fig. 9. Fitted normalized $\mathrm{CO}_{2}$ concentration profiles at $10 \mathrm{MPa} 303 \mathrm{~K}$. (a) $\dot{V}_{\mathrm{CO}_{2}}=49.2 \mu \mathrm{L} \cdot \mathrm{min}^{-1}$ (b) $\dot{V}_{\mathrm{H}_{2} \mathrm{O}}=110 \mu \mathrm{L} \cdot \mathrm{min}^{-1}$.

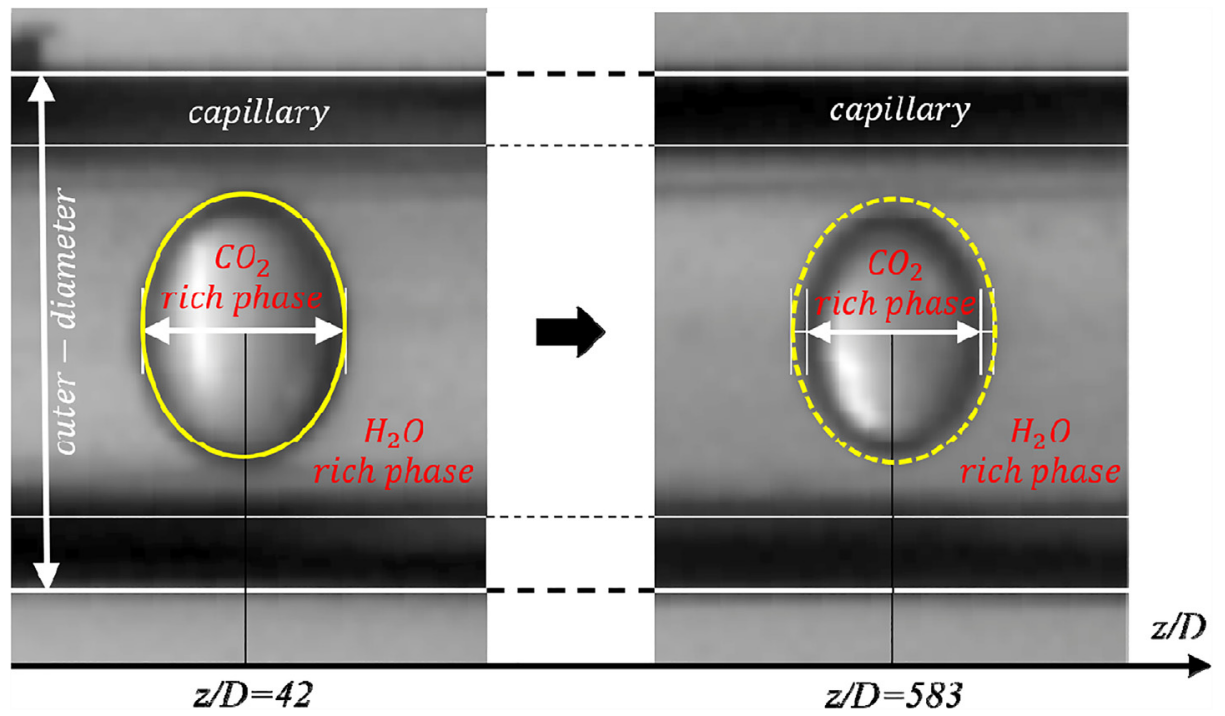

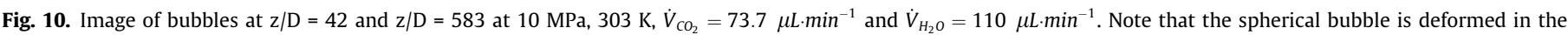

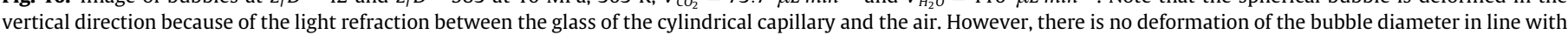
the tube axis and of the outer diameter of the capillary. The bubble shrinkage is presented in yellow.

$\rho_{L}\left(T, P, x_{\mathrm{CO}_{2}}\right)=\frac{\rho_{\mathrm{H}_{2} \mathrm{O}}^{o}(T, P)}{1-w_{\mathrm{CO}_{2}}\left(1-\frac{v_{\mathrm{CO}_{2}}^{a}(T) \rho_{\mathrm{H}_{2} O}^{o}(T, P)}{M_{\mathrm{CO}_{2}}}\right)}$

where $w_{\mathrm{CO}_{2}}$ is the mass fraction of $\mathrm{CO}_{2}$ and $\rho_{\mathrm{H}_{2} \mathrm{O}}^{o}(T, P)$ is the density of pure $\mathrm{H}_{2} \mathrm{O}$ which is determined using the correlation of Batzle and Wang (1992) given by Eq. (14)

$$
\begin{aligned}
\rho_{\mathrm{H}_{2} \mathrm{O}}^{o}(T, P)= & 1+10^{-6} \\
& \times\left(-80 T-3.3 \vartheta^{2}+0.00175 \vartheta^{3}+489 p-2 \vartheta p\right. \\
& \left.+0.016 \vartheta^{2} p-1.3 \times 10^{-5} \vartheta^{3} p-0.333 p^{2}-0.002 \vartheta p^{2}\right)
\end{aligned}
$$

where $p$ is pressure in $\mathrm{MPa}, \vartheta$ is temperature in ${ }^{\circ} \mathrm{C}$ and $\rho_{\mathrm{H}_{2} \mathrm{O}}^{o}$ in $\mathrm{g} /$ $\mathrm{cm}^{3}$.

\subsection{Determination of the volumetric mass transfer coefficient $\boldsymbol{k}_{\mathbf{L}} \boldsymbol{a}_{\mathbf{L}}$}

From Eq. (2), the volumetric mass transfer coefficient can be expressed as Eq. (15).

$k_{L} a_{L}=\frac{U_{T P}}{\left(C_{\mathrm{CO}_{2}}^{*}-C_{\mathrm{CO}_{2}}\right)} \frac{d C_{\mathrm{CO}_{2}}}{d z}$ 


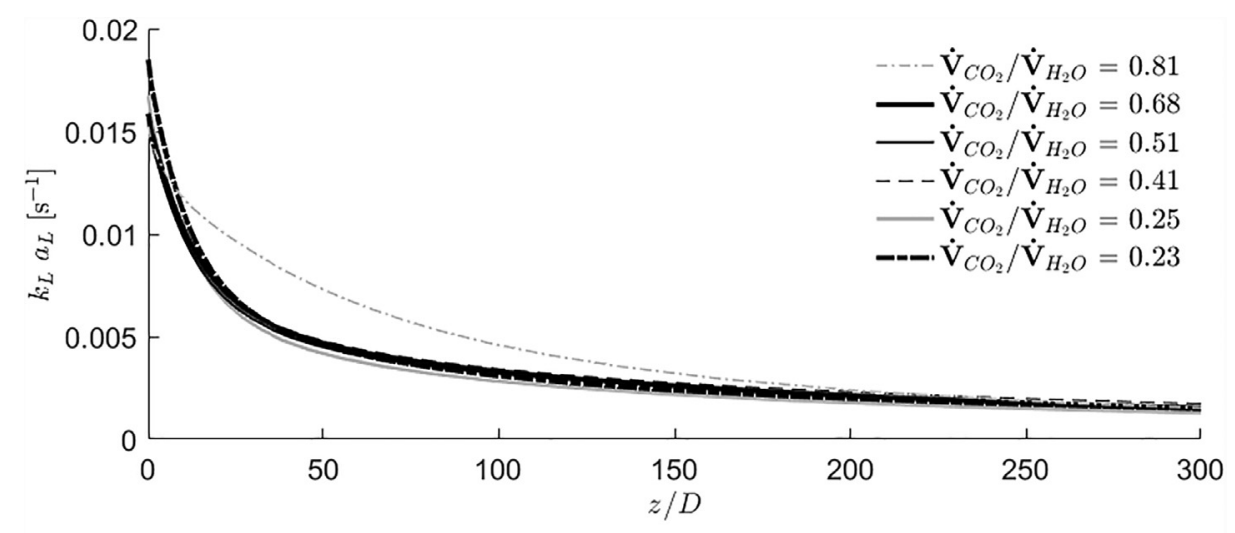

(a)

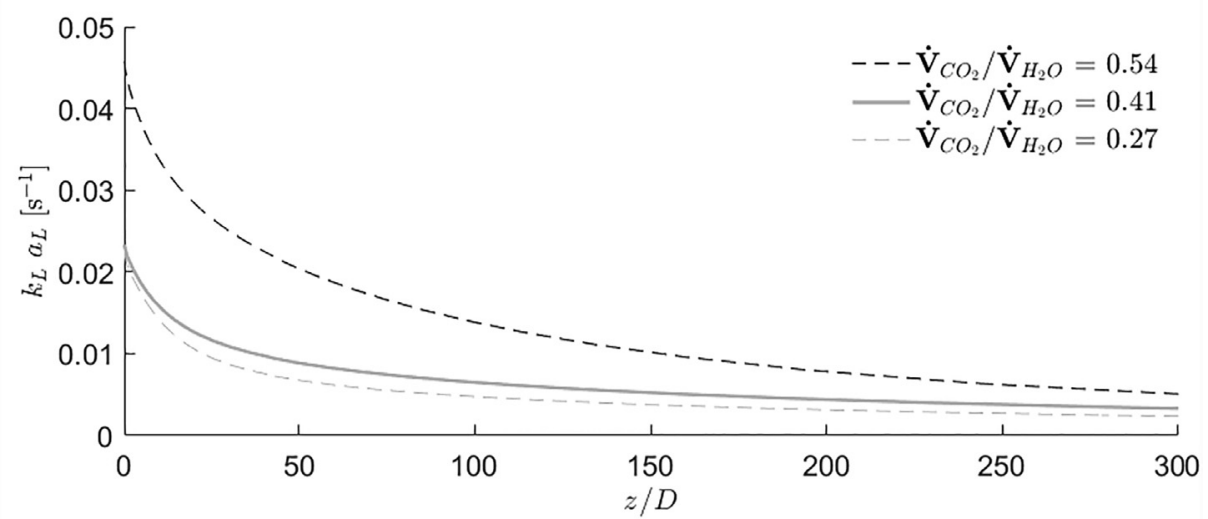

(b)

Fig. 11. Volumetric mass transfer coefficient profiles at $8 \mathrm{MPa}$ and $303 \mathrm{~K} .(a) \dot{V}_{\mathrm{CO}_{2}}=40.5 \mu \mathrm{L} \cdot \mathrm{min}^{-1}$, (b) $\dot{V}_{\mathrm{H}_{2} \mathrm{O}}=200 \mu L \cdot \mathrm{min}^{-1}$.

This equation is based on the unit cell model assuming (H1) to (H5) only. It will be shown that the hypothesis (H6), i.e. assuming that $k_{L} a_{L}$ is constant along the length of the capillary tube, results in significant error on the $k_{L} a_{L}$ values in the case of this study. The first derivative of the $\mathrm{CO}_{2}$ concentration in the $\mathrm{H}_{2} \mathrm{O}$-rich phase, $\frac{d C_{\mathrm{CO}_{2}}}{d z}$, is obtained by filtering the experimental concentration data using fast Fourier transform (FFT) as shown in Appendix B.

\section{Application of the experimental method to $\mathrm{CO}_{2}-\mathrm{H}_{2} \mathrm{O}$ mass transfer under high-pressure conditions}

In order to demonstrate the use of the experimental method presented here, this section presents examples of Raman spectroscopy measurements and data analysis to obtain the volumetric mass transfer coefficient for a segmented flow composed of $\mathrm{CO}_{2}$ rich and $\mathrm{H}_{2} \mathrm{O}$-rich phases in a capillary tube at pressures of $8 \mathrm{MPa}, 9 \mathrm{MPa}$ and $10 \mathrm{MPa}$, as well as a range of flow rates.

Fig. 6 shows an example of the experimental concentration data (normalised by the value at saturation) and the corresponding profiles obtained by FFT filtering as a function of the axial distance from the contacting zone in the capillary tube for $10 \mathrm{MPa}, 303 \mathrm{~K}$ and a constant $\mathrm{H}_{2} \mathrm{O}$ flowrate $\left(110 \mu \mathrm{L} \cdot \mathrm{min}^{-1}\right)$. The error bars correspond to \pm 3 standard deviations (see Appendix A for uncertainty calculations). The average deviation between the fitted concentrations and the experimental values of all the conditions studied in this paper do not exceed $1 \%$. This figure clearly shows that the FFT filtering method correctly represents the $\mathrm{CO}_{2}$ concentration in the $\mathrm{H}_{2} \mathrm{O}$-rich phase at each measurement point in the capillary tube. Considering this, in subsequent Figs. 7-9, only the fitted curves are shown in order to facilitate reading.

\subsection{Concentration profiles}

Figs. 7-9 show the normalized fitted $\mathrm{CO}_{2}$ concentration profiles versus the normalized axial position in the capillary $(z / D)$ at $303 \mathrm{~K}$ and $8 \mathrm{MPa}, 9 \mathrm{MPa}$ and $10 \mathrm{MPa}$, respectively. At each pressure, either the volumetric flow rate of $\mathrm{CO}_{2}$ or of $\mathrm{H}_{2} \mathrm{O}$ was kept constant, whilst the flow rate of the other phase was varied. The flow rate ratio therefore provides the basis for comparison. Indeed, the volumetric flowrate ratio is a key parameter for characterising hydrodynamics in segmented flows in small channels. Droplet and bubble growth mechanisms and lengths in microchannels have been widely studied (see for example Garstecki et al. (2006), van Steijn et al. (2007), Abadie et al. (2012)). In such studies, it has been shown that bubble length, $L_{B}$, and liquid slug length, $L_{S}$, increase linearly with $\frac{\dot{V}_{\mathrm{CO}_{2}}}{\dot{\mathrm{H}}_{\mathrm{H}_{2} \mathrm{O}}}$ and $\frac{\dot{V}_{\mathrm{H}_{2} \mathrm{O}}}{\dot{V}_{\mathrm{CO}_{2}}}$, respectively.

For all pressures, it is observed that when $\frac{\dot{V}_{\mathrm{CO}_{2}}}{\dot{V}_{\mathrm{H}_{2} \mathrm{O}}}$ decreases, thermodynamic equilibrium is reached further along the capillary tube away from the contacting point. When $\frac{\dot{V}_{\mathrm{CO}_{2}}}{\dot{V}_{\mathrm{H}_{2} \mathrm{O}}}$ decreases, the bubble length $L_{B}$ decreases and the slug length $L_{S}$ increases. As a consequence, the interfacial area for mass transfer decreases. In addition, there is a larger amount of $\mathrm{H}_{2} \mathrm{O}$ in a liquid slug to be saturated whereas a lesser amount of $\mathrm{CO}_{2}$ is available in the $\mathrm{CO}_{2}$-rich bubble. Both of these contributions result in the fact that thermodynamic equilibrium is reached further along the capillary from the contacting zone.

\subsection{Volumetric mass transfer coefficient profiles}

Figs. 11-13 show the volumetric liquid mass transfer coefficient $k_{L} a_{L}$, determined with Eq. (15), along the length of the capillary 


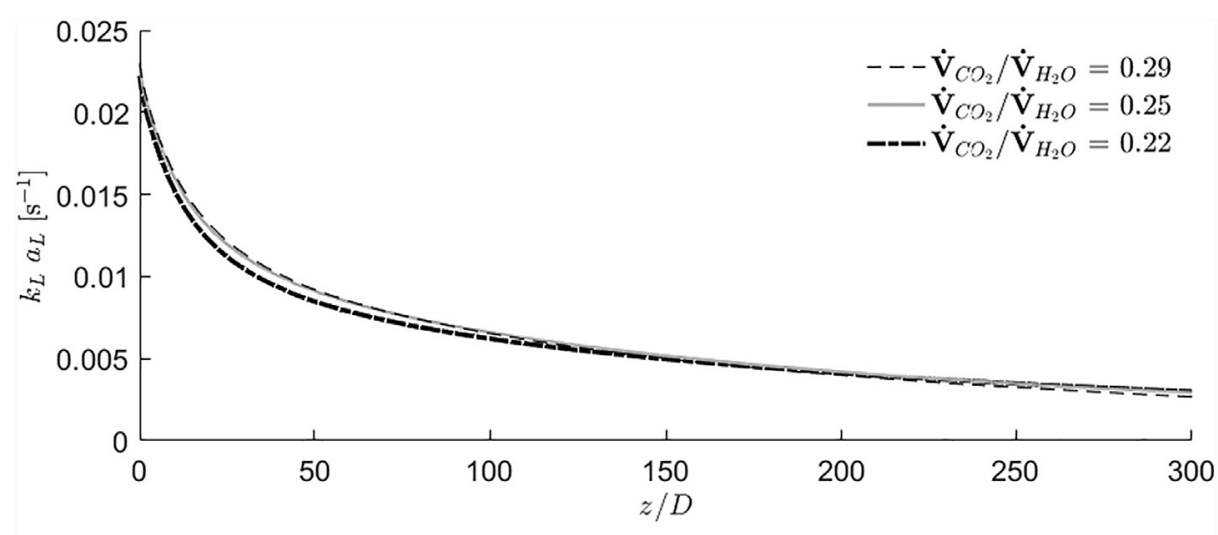

(a)

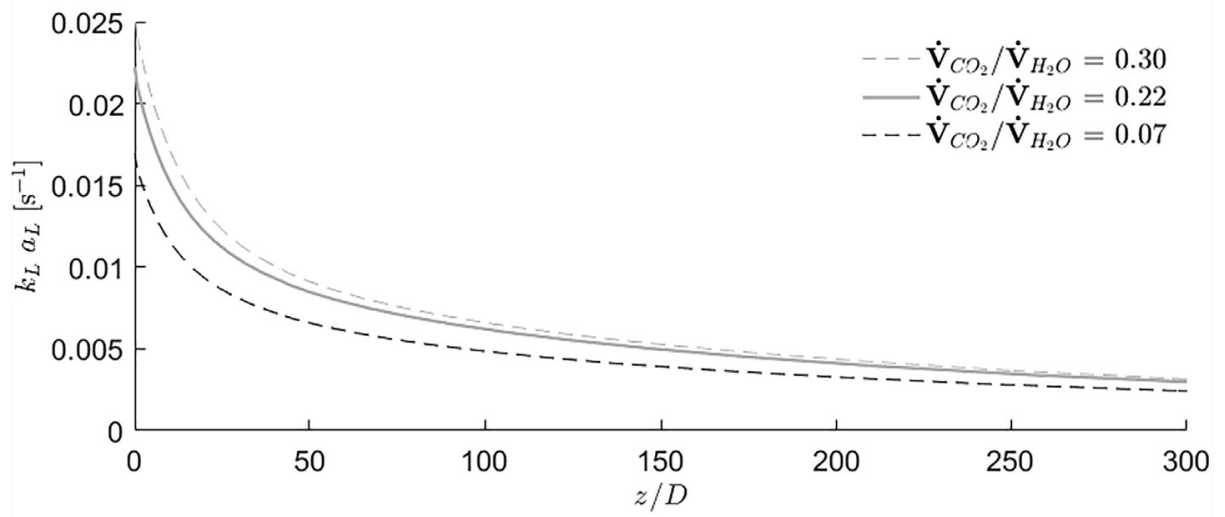

(b)

Fig. 12. Volumetric mass transfer coefficient profiles at $9 \mathrm{MPa}$ and $303 \mathrm{~K}$. (a) $\dot{V}_{\mathrm{CO}_{2}}=38.2 \mu \mathrm{L} \cdot \mathrm{min}^{-1}$, (b) $\dot{V}_{\mathrm{H}_{2} \mathrm{O}}=170 \mu \mathrm{L} \cdot \mathrm{min}^{-1}$.

tube. Firstly, it is seen that $k_{L} a_{L}$ is not constant along the capillary tube. This observation proves that hypothesis (H6) (i.e. $k_{L} a_{L}$ is constant along the tube, and either a decrease in $a_{L}$ is compensated by an increase in $k_{L}$, or $k_{L}$ and $a_{L}$ are both assumed constant, which is often assumed in the unit cell model), is not valid. Indeed, when using hypothesis (H6), the value of $k_{L} a_{L}$ at $z / D=100$ gives an average error of $35 \%$ compared with the value obtained without (H6). $k_{L} a_{L}$ decreases along the capillary tube between $z / D=0$ and $z /$ $D=600$ by approximately a factor of 8 . If this decrease in $k_{L} a_{L}$ is due to a decrease in $a_{L}$ only, then this corresponds to a decrease in the bubble diameter of a factor $\sqrt{8} \approx 2.83$ (considering a spherical bubble and a water-rich slug with constant volume). However, such a significant decrease in bubble size between the contacting zone and the outlet of the capillary tube was not observed in the experiments as it can be seen from Fig. 10. Hence, this implies that $k_{L}$ must also be decreasing along the length of the capillary tube.

It can also be seen in Figs. 11-13 that the rate of mass transfer is significantly higher closer to the contacting zone where $\mathrm{CO}_{2}$-rich bubbles are formed. This is in agreement with the concentration profiles in Figs. $7-9$ where it can be seen that more than $20 \%$ of the thermodynamic equilibrium is reached during the bubble formation stage $(z / D<20)$. The enhanced mass transfer at the bubble formation stage may be described by a difference in hydrodynamics between the bubble formation stage, which is a transient process, and the more or less stable segmented flow in the rest of the capillary tube. Indeed, in the transient bubble formation process, a bubble will grow and then be pinched-off, which will increase the liquid flow intermittently in the vicinity of the interface and consequently promote mass transfer.

A comparison of the experiments also shows that for constant $\dot{V}_{\mathrm{CO}_{2}}$ or $\dot{V}_{\mathrm{H}_{2} \mathrm{O}}$, increasing $\frac{\dot{V}_{\mathrm{CO}_{2}}}{\dot{V}_{\mathrm{H}_{2} \mathrm{O}}}$ leads to an increase of $k_{L} a_{L}$. This may explained by the fact that an increase in $\frac{\dot{V}_{\mathrm{CO}_{2}}}{\dot{V}_{\mathrm{H}_{2} \mathrm{O}}}$ results in an increase of the bubble length, $L_{B}$, (and consequently the bubble volume, $V_{B}$ ) and a decrease of the liquid slug length, $L_{S}$. A decrease in slug length has previously been shown to increase the liquid slug recirculation (Leung et al., 2010, Zaloha et al., 2012, Abadie, 2013). It is expected that this would result in an enhanced renewal of the fluid-liquid interface and in turn increase the mass transfer coefficient $k_{L}$. Moreover, Abadie (2013) and Martin et al. (2018) showed that for both ambient pressure and high-pressure flows, the ratio between $L_{B}$ and the total length of a unit cell, $L_{B}+L_{S}$, depends on $\frac{U_{F}}{U_{L}}$, and therefore $\frac{\dot{V}_{\mathrm{CO}_{2}}}{\dot{V}_{\mathrm{H}_{2} \mathrm{O}}}$ as described by Eq. (16):

$\frac{L_{B}}{L_{B}+L_{S}}=\frac{\frac{U_{F}}{U_{L}}}{\beta+\frac{U_{F}}{U_{L}}}$

where $\beta$ is a constant.

Eq. (16) shows that when $\frac{\dot{V}_{\mathrm{CO}_{2}}}{\dot{V}_{\mathrm{H}_{2} \mathrm{O}}}$ increases, $\frac{L_{B}}{L_{B}+L_{S}}$ also increases, which corresponds to an increase of $a_{L}$. Hence, an increase in $\frac{\dot{V}_{\mathrm{CO}_{2}}}{\dot{V}_{\mathrm{H}_{2} \mathrm{O}}}$ causes both $k_{L}$ and $a_{L}$ to increase, which is in agreement with the experimental observations that $k_{L} a_{L}$ is higher when $\frac{\dot{V}_{\mathrm{CO}_{2}}}{\dot{V}_{\mathrm{H}_{2} \mathrm{O}}}$ is higher.

Finally, it can be pointed out that values of the volumetric mass transfer coefficients measured here are between $2.10^{-3} \mathrm{~s}^{-1}$ and $5.10^{-2} \mathrm{~s}^{-1}$, which are the same order of magnitude as values obtained in other microfluidic systems of this diameter and in the same range of Reynolds number (Susanti et al., 2016). 


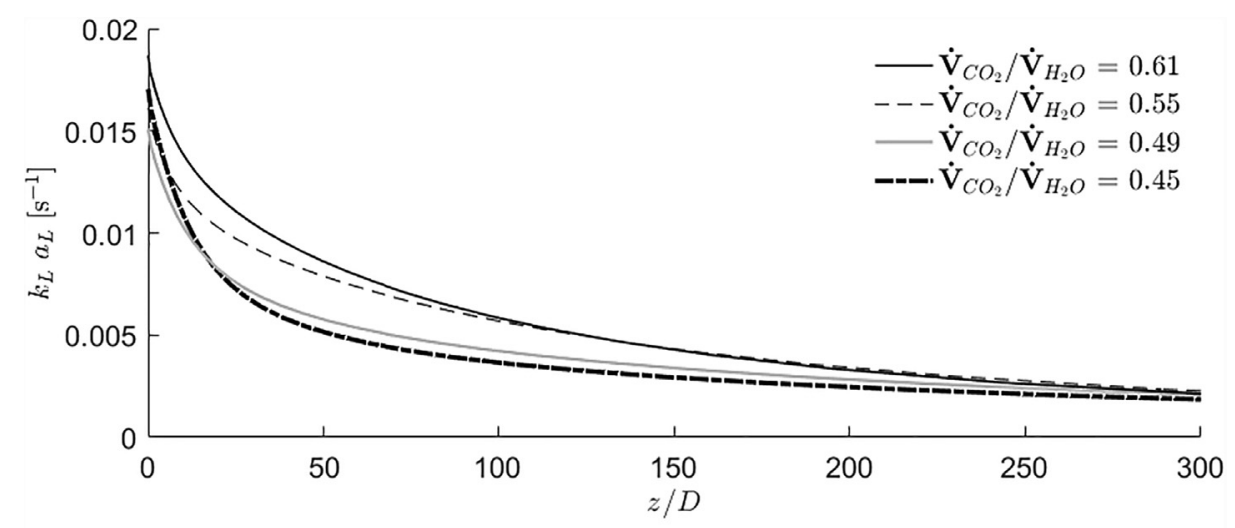

(a)

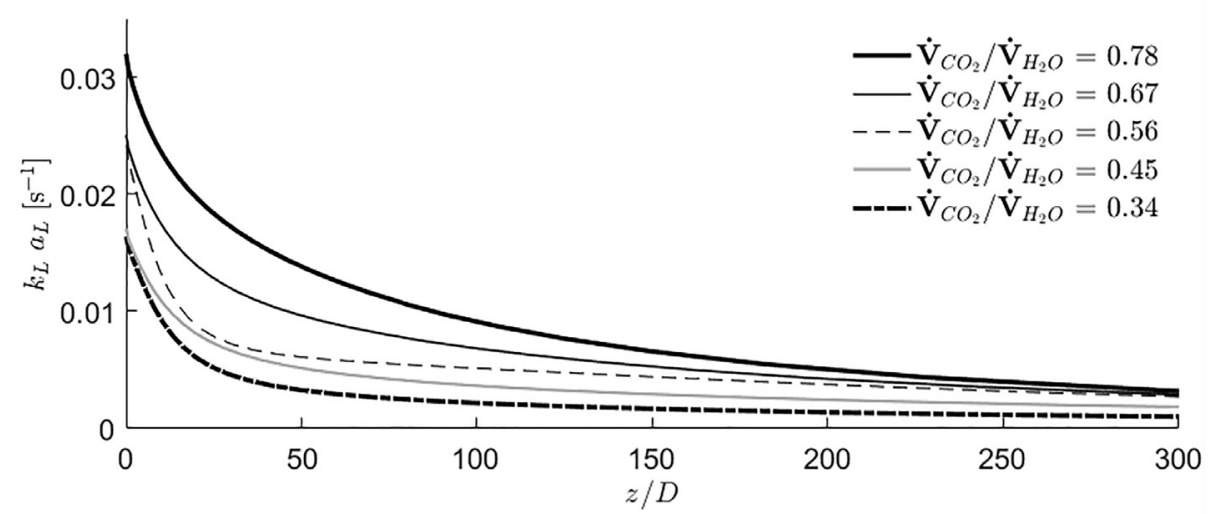

(b)

Fig. 13. Volumetric mass transfer coefficient profiles at $10 \mathrm{MPa}$ and $303 \mathrm{~K}$. (a) $\dot{V}_{\mathrm{CO}_{2}}=49.2 \mu L \cdot \mathrm{min}^{-1}$, (b) $\dot{V}_{\mathrm{H}_{2} \mathrm{O}}=110 \mu L \cdot \mathrm{min}^{-1}$.

\section{Conclusion}

A new experimental method to determine mass transfer coefficients in two-phase flow at elevated pressure and moderate temperature in a micro-capillary tube has been presented. It is based on the measurement of the molar ratio of different species in one of the phases using Raman spectroscopy. The species concentration, mixture density and the mass transfer coefficient are then determined using appropriate thermodynamic models and the unit cell model for mass transfer in segmented two-phase flow. The novelty of this method is that it allows the measurement of local values of the mass transfer coefficient at different positions along capillary tube and it takes into account variations in fluid properties due to high-pressure conditions. The results obtained with this technique can serve as a design tool for new types of microreactors where mass transfer is a key parameter and also as a fundamental tool in order to investigate mass transfer behaviour of different binaries in high-pressure systems.

The method has been applied to a $\mathrm{CO}_{2}-\mathrm{H}_{2} \mathrm{O}$ flow at $303 \mathrm{~K}$ and pressures of $8 \mathrm{MPa}, 9 \mathrm{MPa}$ and $10 \mathrm{MPa}$. The $k_{L} a_{L}$ values obtained are in the range $10^{-3}-10^{-2} \mathrm{~s}^{-1}$, which agree with the values in the literature and illustrate the reliability of the technique. It has also been shown that $k_{L} a_{L}$ is not constant and that it decreases along the length of the capillary tube; this decrease is expected to be due to both a decrease in $k_{L}$ and $a_{L}$. This result clearly shows that the assumption that $k_{L} a_{L}$ is constant along the tube length, which is commonly used in the unit cell model, is in fact incorrect (35\% of error in average).

Future studies will focus on the effects of pressure and the temperature on mass transfer with an objective of developing dimen- sionless correlations of the volumetric mass transfer coefficient. Indeed, this technique will be of significant interest for studying mass transfer in other binary systems such as ethanol and $\mathrm{CO}_{2}$ by measuring in both phases. In ethanol and $\mathrm{CO}_{2}$ systems, mass transfer occurs from the liquid phase to the fluid phase, also from the fluid phase to the liquid phase and the density of both phases change during the mass transfer. Further developments of this technique will include the combination of the Raman spectroscopy measurements with high speed imaging of the flow. This will enable the volume of the bubbles and their velocities at each position in the capillary tube to be measured. The former will give the access to the specific surface $a_{L}$ of the dispersed phase and allow the individual contributions of $k_{L}$ and $a_{L}$ in the volumetric mass transfer coefficient $k_{L} a_{L}$ to be assessed.

\section{CRediT authorship contribution statement}

T. Deleau: Conceptualization, Data curation, Formal analysis, Investigation, Methodology, Writing - original draft. M.H.H. Fechter: Data curation, Investigation. J-J. Letourneau: Conceptualization, Formal analysis, Supervision, Writing - review \& editing, Funding acquisition. S. Camy: Conceptualization, Supervision, Writing - review \& editing, Funding acquisition. J. Aubin: Conceptualization, Supervision, Writing - review \& editing, Funding acquisition. A.S. Braeuer: Conceptualization, Formal analysis, Supervision, Writing - review \& editing. F. Espitalier: Conceptualization, Supervision, Writing - review \& editing, Funding acquisition. 


\section{Declaration of Competing Interest}

The authors declare that they have no known competing financial interests or personal relationships that could have appeared to influence the work reported in this paper.

\section{Acknowledgements}

The project leading to this result has received funding from the Occitanie region (France), MUSYS project (ALDOCT-000149-2017 001788). The authors also gratefully acknowledge the doctoral school MEGeP for funding relating to T.D.'s stay at the Institute of Thermal, Environmental, and Resources Process Engineering, ITUN (Germany) and ITUN for access to the experimental setup.

\section{Appendix A. Uncertainty calculations}

This section deals with the propagation of uncertainties from the acquisition of the Raman spectra to the concentration calculations. In each experiment, 16 spectra have been recorded for each of the ten measurement points. From these, $16 \times 10$ molar ratios $\frac{n_{\mathrm{CO}_{2}}}{n_{\mathrm{H}_{2} \mathrm{O}}}$ (or molar fraction ratio) are obtained.

\section{A.1. Experimental uncertainty of the z-position in the capillary tube}

In order to compute the error of the z-position where the measurement is made, the following method was used.

Fig. 14 shows the observed image of the laser passing through the capillary tube on the black optical table. The length of the measurement spot is known $\left(L_{1}=1 \mathrm{~cm}\right)$ and the length of the image, $L_{2}$, is measured. The magnification of the capillary tube image, $G$, is then computed with Eq. (17).

$G=\frac{L_{2}}{L_{1}}=\frac{I D_{2}}{I D_{1}} \approx 30$

When the laser is focused in the capillary (right sketch of Fig. 14), the image is checked to be symmetrical, which means that the laser is well positioned in the measurement spot. It is considered that the maximum error here is $2 \mathrm{~cm}$, which corresponds to an error of $667 \mu \mathrm{m}$ in the z-position. This error is negligible and does not affect the concentration measurements.

\section{A.2. Experimental uncertainty on concentration}

For each experiment, a standard normal distribution test is performed on the molar ratio values $\left(r=\frac{n_{\mathrm{H}_{2 O}}}{n_{\mathrm{CO}_{2}}}\right)$, the results are shown in Fig. 15. Each group of data follows a standard normal distribution, hence, the standard deviation $\sigma_{r}$ can be interpreted as a standard deviation of a normal distribution.

Eq. (19) gives the approximation of the standard deviation $\sigma_{\mathrm{C}_{2}}$ calculated with the standard deviations of both the molar ratio, $r$, and the liquid mixture density, $\rho_{L}$. This approximation is taken because the values of $r$ and $\rho_{L}$ are near their mean values and $\sigma_{r}$ (respectively $\sigma_{\rho_{L}}$ ) is small compared with $r\left(\rho_{L}\right)$. Furthermore, $\frac{\partial f}{\partial r}$ (respectively $\frac{\partial f}{\partial \rho_{L}}$ ) are linear within the interval $\pm \sigma_{r}\left( \pm \sigma_{\rho_{L}}\right)$ about $r$ $\left(\rho_{L}\right)$.

$$
C_{\mathrm{CO}_{2}}=\frac{\rho_{L}\left(T, P, x_{\mathrm{CO}_{2}}\right)}{M_{\mathrm{CO}_{2}}+\frac{n_{\mathrm{H}_{20}}}{n_{\mathrm{CO}_{2}}} M_{\mathrm{H}_{2} \mathrm{O}}}=f\left(\frac{n_{\mathrm{H}_{20}}}{n_{\mathrm{CO}_{2}}}, \rho_{L}\right)=f\left(r, \rho_{L}\right)
$$

${\sigma_{\mathrm{CO}_{2}}}^{2}=\left(\frac{\partial f}{\partial r}\right)_{r=r}^{2} \sigma_{r}^{2}+\left(\frac{\partial f}{\partial \rho_{L}}\right)_{\rho_{L}=\rho_{L}}^{2} \sigma_{\rho_{L}}^{2}$

Random sampling in the normal distribution of $r$ and $\rho_{L}$ allows computation of a representative sample of $C_{\mathrm{CO}_{2}}$. It has been shown that the concentration distribution also follows a normal law. Consequently, the standard deviation $\sigma_{\mathrm{C}_{\mathrm{CO}_{2}}}$ represented in Fig. 6 can be interpreted as the standard deviation of a normal distribution. The value of the standard deviation $\sigma_{\mathrm{C}_{\mathrm{C}_{2}}}$ which take into account the variations of the molar ratios (including the error during the calibration step) and the variations of the mixture density, does not exceed $7 \%$ of the concentration value. However, this deviation can be drastically reduced with a binary system where the calibration step is easier than the one with the $\mathrm{CO}_{2}-\mathrm{H}_{2} \mathrm{O}$ system because the solubility of $\mathrm{CO}_{2}$ in the $\mathrm{H}_{2} \mathrm{O}$ rich phase is small (and therefore reduces the resolution of the calibration curve). The contribution of temperature and pressure measurements on the concentrations obtained with this method was verified by a random sampling in the normal distribution of $\mathrm{T}$ and $\mathrm{P}$. The results show that the concentration values are shifted by less than $0.05 \%$ of the mean value, which is highly negligible compared with error from the molar ratio and from the density model.

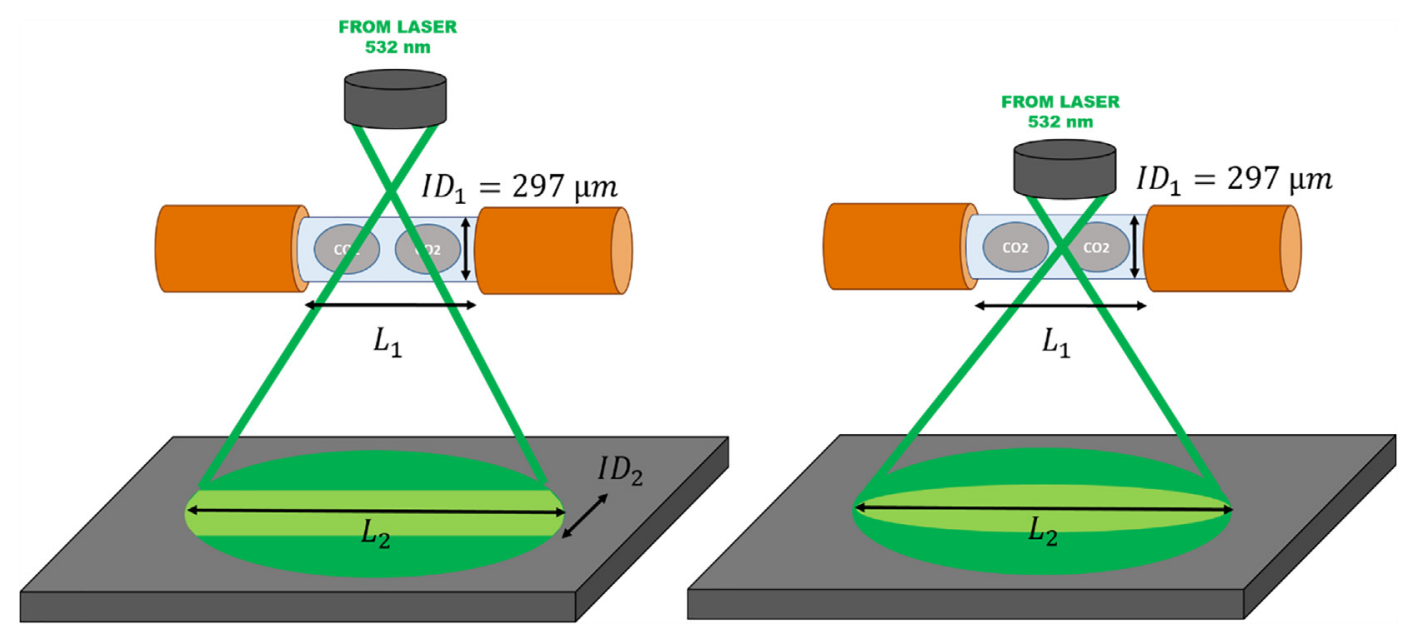

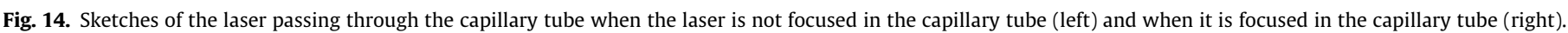



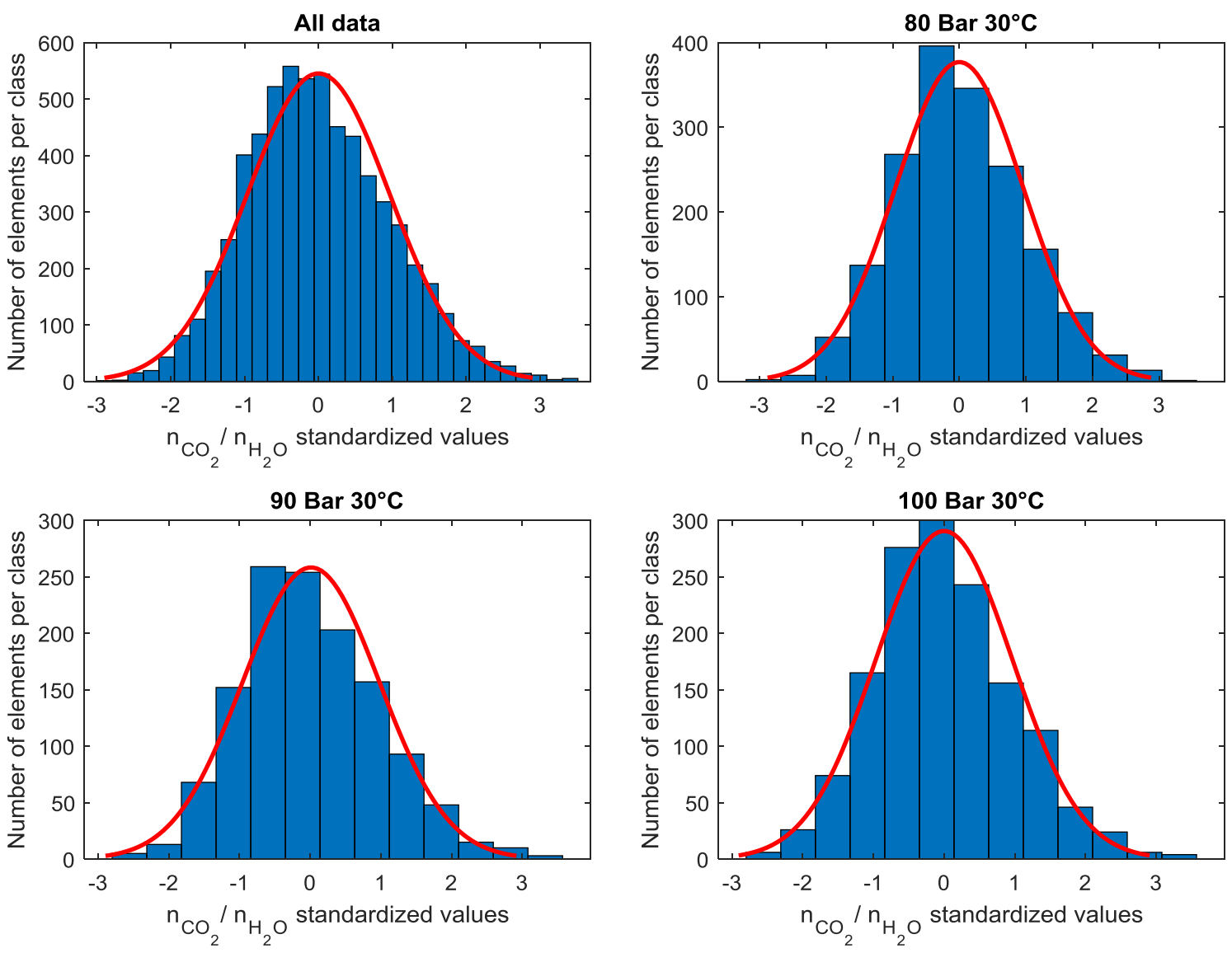

Fig. 15. Standardized class distribution of $\frac{\mathrm{n}_{\mathrm{H}_{20}}}{\mathrm{n}_{\mathrm{CO}_{2}}}$ values (blue) and standardized normal distribution (red).

\section{Appendix B. Fast Fourier transform (FFT) filtering}

As it can be observed from Eq. (15), the $k_{L} a_{L}$ calculation requires estimation of the value of the first derivative at each point of the curve $\mathrm{C}_{\mathrm{CO}_{2}}$ versus $z$. The precision of a derivative between two experimental data points is not sufficient to proceed to a raw calculation of these derivatives. In fact, as shown on Fig. 6, the data present Gaussian "noise" in the $C_{\mathrm{CO}_{2}}$ versus $z$ curves. These curves therefore have to be filtered and smoothed before any estimation of the derivative. Several filtering and smoothing techniques have been tested. The best results have been obtained with the Fast Fourier Transform (Balac, 2011). The selection was based on the visual smoothing appearance and objective criteria consisting in the weighted least squares (square root of the sum of the square residuals between experimental and filtering values weighted by the inverse of the standard deviation). This technique consists of several steps.

- Firstly, two points are added to each set of results $\left(z, C_{\mathrm{CO}_{2}}\right)$ : the initial point $(0,0)$ and a theoretical final one $\left(+\infty, C_{\mathrm{CO}_{2}}^{*}\right)$.

- The following variable substitutions are then performed: $Z=1 /(1+\gamma z)$ and $Y=C_{\mathrm{CO}_{2}} / C_{\mathrm{CO}_{2}}^{*}$. The new variables are confined in the range $[0,1] x[0,1]$, and the parameter $\gamma(0<\gamma<1)$ allows a better spreading of these new data on $[0,1]$.

- The values used for the discussion on the comparative experimental results mostly concern the first part of the curve, i.e. near the point $(0,0)$. Therefore, care should be taken when fitting data in this region. This is why the third step consists in the doubling of the number of points by adding $(-Z,-Y)$ to the curve. This way, the region of interest is located in the middle of the curve, far from eventual boundaries ending point problems.

- The fourth step consists in rotating the curve centred at $(0,0)$ by an angle of $-\pi / 4$. Following this, a continuous periodic curve is obtained that greatly improves the selection of frequencies after the FFT.

- Resampling is carried out at the points $(Z, Y)$ of this curve by linear interpolation in order to obtain a new set of equally-spaced points on the z-axis. In order to respect the Shannon theorem, $2^{5}$ points were taken. A discrete Fourier transform using a FFT algorithm is then performed.

- From the amplitude spectrum of the Fourier transform, between 2 and 4 frequencies of greater amplitudes are selected (taking the smallest objective criteria). The inverse Fourier transform is then carried out with these selected pairs of frequency and amplitude, leading to a new set of filtered $(Z, Y)$.

- Finally, a reverse rotation and a reverse variable substitution is performed and the final filtered and smoothed curve of $C_{\mathrm{CO}_{2}}$ versus $z$ is obtained. These filtered points are used to estimate the first derivative of $C_{\mathrm{CO}_{2}}$ needed for $k_{L} a_{L}$ calculation.

\section{References}

Abadie, Thomas, 2013. Hydrodynamics of Gas-Liquid Taylor Flow in Microchannels. Phd. http://ethesis.inp-toulouse.fr/archive/00002504/.

Abadie, T., Aubin, J., Legendre, D., Xuereb, C., 2012. Hydrodynamics of Gas-Liquid Taylor Flow in Rectangular Microchannels. Microfluid. Nanofluid. 12 (January), 355-369. https://doi.org/10.1007/s10404-011-0880-8. 
Andersen, G., Probst, A., Murray, L., Butler, S., 1992. An Accurate PVT Model for Geothermal Fluids as Represented by $\mathrm{H} 2 \mathrm{O}-\mathrm{NaCl}-\mathrm{CO}_{2}$. In: Mixtures, Proceedings 17th Workshop on Geothermal Reservoir Engineering, pp. 239-248.

Anderson, G.R., 1977. The Raman Spectra of Carbon Dioxide in Liquid Water and Water-D2. J. Phys. Chem. 81 (3), 273-276. https://doi.org/10.1021/ j100518a017.

Bachu, S., Adams, J.J., 2003. Sequestration of $\mathrm{CO}_{2}$ in Geological Media in Response to Climate Change: Capacity of Deep Saline Aquifers to Sequester $\mathrm{CO}_{2}$ in Solution. Energy Convers. Manage. 44 (20), 3151-3175. https://doi.org/10.1016/S01968904(03)00101-8.

Balac, Stéphane, 2011. La transformée de Fourier vue sous l'angle du calcul numérique, January. https://cel.archives-ouvertes.fr/cel-01862054.

van Baten, J.M., Krishna, R., 2004. CFD Simulations of Mass Transfer from Taylor Bubbles Rising in Circular Capillaries. Chem. Eng. Sci. 59 (12), 2535-2545. https://doi.org/10.1016/j.ces.2004.03.010.

Batzle, M., Wang, Z., 1992. Seismic Properties of Pore Fluids. Geophysics 57 (11), 1396-1408. https://doi.org/10.1190/1.1443207.

Ben-Nasr, Hedi, Coenen, Hubert, 1994. Process for the quasi-continuous decaffeination of raw coffee. United States US5338575A, filed 5 May 1993 , and issued 16 August 1994. https://patents.google.com/patent/US5338575A/en.

Bercic, G., Pintar, A., 1997. The Role of Gas Bubbles and Liquid Slug Lengths on Mass Transport in the Taylor Flow through Capillaries. Chem. Eng. Sci. 52 (21), 37093719. https://doi.org/10.1016/S0009-2509(97)00217-0.

Bird, R.B., 2002. Transport Phenomena. Appl. Mech. Rev. 55 (1), R1-R4. https://doi $\operatorname{org} / 10.1115 / 1.1424298$.

Brunner, G. 2005. Supercritical fluids: technology and application to food processing. J. Food Eng. 67 (1-2), 21-33 https://linkinghub.elsevier.com/ retrieve/pii/S0260877404003383. https://doi.org/10.1016/j. jfoodeng.2004.05.060.

Dietrich, N., Loubière, K., Jimenez, M., Hébrard, G., Gourdon, C., 2013. A New Direct Technique for Visualizing and Measuring Gas-Liquid Mass Transfer around Bubbles Moving in a Straight Millimetric Square Channel. Chemical Engineering Science, 11th International Conference on Gas-Liquid and Gas-Liquid-Solid Reactor Engineering, 100 (August), 172-82. https://doi.org/10.1016/j.ces.2013. 03.041.

Enick, R.M., Klara, S.M., 1990. $\mathrm{CO}_{2}$ Solubility in Water and Brime under Reservoir Conditions. Chem. Eng. Commun. 90 (1), 23-33. https://doi.org/10.1080/ 00986449008940574

Eskin, D., Mostowfi, F., 2012. A Model of a Bubble Train Flow Accompanied with Mass Transfer through a Long Microchannel. Int. J. Heat Fluid Flow 33 (1), 147155. https://doi.org/10.1016/j.ijheatfluidflow.2011.11.001.

Ganapathy, H., Shooshtari, A., Dessiatoun, S., Alshehhi, M., Ohadi, M., 2014. Fluid Flow and Mass Transfer Characteristics of Enhanced $\mathrm{CO}_{2}$ Capture in Minichannel Reactor. Appl. Energy 119, 43-56. https://doi.org/10.1016/j. apenergy.2013.12.047.

Garcia, Julio E., 2001. Density of Aqueous Solutions of CO2, October. https:/ escholarship.org/uc/item/6dn022hb.

Garstecki, P., Fuerstman, M.J., Stone, H.A., Whitesides, G.M., 2006. Formation of Droplets and Bubbles in a Microfluidic T-Junction-Scaling and Mechanism of Break-Up. Lab Chip 6 (3), 437-446. https://doi.org/10.1039/B510841A.

Heiszwolf, J.J., Kreutzer, M.T., van den Eijnden, M.G., Kapteijn, F., Moulijn, J.A., 2001 Gas-Liquid Mass Transfer of Aqueous Taylor Flow in Monoliths. Catal. Today, Srtuctured Catalysts and Reactors 69 (1), 51-55. https://doi.org/10.1016/S0920 5861(01)00354-6.

Irandoust, S., Ertlé, S., Andersson, B., 1992. Gas-liquid mass transfer in taylor flow through a capillary. Can. J. Chem. Eng. 70 (1), 115-119. https://doi.org/10.1002 cjce:5450700116.

Kim, H.-J., Lee, S.-B., Park, K.-A., Hong, I.-K., 1999. Characterization of Extraction and Separation of Rice Bran Oil Rich in EFA Using SFE Process. Sep. Purif. Technol. 15 (1), 1-8. https://doi.org/10.1016/S1383-5866(98)00048-3

Klima, T.C., Braeuer, A.S., 2019. Vapor-Liquid-Equilibria of Fuel-Nitrogen Systems at Engine-like Conditions Measured with Raman Spectroscopy in Micro Capillaries. Fuel 238 (February), 312-319. https://doi.org/10.1016/ j.fuel.2018.10.108.

Knez, Ž., Hrnčič, M.K., Čolnik, M., Škerget, M., 2018. Chemicals and Value Added Compounds from Biomass Using Sub- and Supercritical Water. J. Supercrit. Fluids 133 (March), 591-602. https://doi.org/10.1016/j.supflu.2017.08.011. Biomass Fractionation by Subcritical and Supercritical Water.

Kuhn, S., Jensen, K.F., 2012. A pH-Sensitive Laser-Induced Fluorescence Technique To Monitor Mass Transfer in Multiphase Flows in Microfluidic Devices. Ind. Eng Chem. Res. 51 (26), 8999-9006. https://doi.org/10.1021/ie300978n.

Lefortier, S.G.R., Hamersma, P.J., Bardow, A., Kreutzer, M.T., 2012. Rapid Microfluidic Screening of $\mathrm{CO}_{2}$ Solubility and Diffusion in Pure and Mixed Solvents. Lab Chip 12 (18), 3387-3391. https://doi.org/10.1039/C2LC40260B.

Lehotay, S.J., 1997. Supercritical Fluid Extraction of Pesticides in Foods. Chromatogr. A 785 (1), 289-312. https://doi.org/10.1016/S0021-9673(97) 00461-5.

Leung, S.S.Y., Liu, Y., Fletcher, D.F., Haynes, B.S., 2010. Heat Transfer in WellCharacterised Taylor Flow. Chem. Eng. Sci. 65 (24), 6379-6388. https://doi.org/ 10.1016/j.ces.2010.09.014.

Liu, D., Wang, S., 2011. Gas-Liquid Mass Transfer in Taylor Flow through Circular Capillaries. Ind. Eng. Chem. Res. 50 (4), 2323-2330. https://doi.org/10.1021/ ie902055p.

Lumia, Guy, Perre, Christian, Aracil, Jean-Marie, 2007. Method for treating and extracting cork organic compounds, with a dense fluid under pressure. United
States US7192490B1, filed 26 September 2000, and issued 20 March 2007. https://patents.google.com/patent/US7192490B1/en.

Luther, S.K., Schuster, J.J., Leipertz, A., Braeuer, A., 2013. Microfluidic Investigation into Mass Transfer in Compressible Multi-Phase Systems Composed of Oil, Water and Carbon Dioxide at Elevated Pressure. J. Supercrit. Fluids 84 (December), 121-131. https://doi.org/10.1016/j.supflu.2013.10.002.

Portela, M., da Silva, N., Letourneau, J.-J., Espitalier, F., Prat, L., 2014. Transparent and Inexpensive Microfluidic Device for Two-Phase Flow Systems with HighPressure Performance. Chem. Eng. Technol. 37 (11), 1929-1937.

Marre, S., Adamo, A., Basak, S., Aymonier, C., Jensen, K.F., 2010. Design and Packaging of Microreactors for High Pressure and High Temperature Applications. Ind. Eng. Chem. Res. 49 (22), 11310-11320. https://doi.org/ 10.1021/ie101346u.

Martin, A., Camy, S., Aubin, J., 2018. Hydrodynamics of $\mathrm{CO}_{2}$-Ethanol Flow in a Microchannel under Elevated Pressure. Chem. Eng. Sci. 178 (March), 297-311. https://doi.org/10.1016/j.ces.2017.12.046.

Martin, A., Teychené, S., Camy, S., Aubin, J., 2016. Fast and Inexpensive Method for the Fabrication of Transparent Pressure-Resistant Microfluidic Chips. Microfluid. Nanofluid. 20 (6), 92. https://doi.org/10.1007/s10404-016-1757-7.

Masmoudi, Y., Ben Azzouk, L., Forzano, O., Andre, J.-M., Badens, E., 2011. Supercritical impregnation of intraocular lenses. J. Supercrit. Fluids 60, 98105 https://linkinghub.elsevier.com/retrieve/pii/S089684461100372X. https:/ doi.org/10.1016/j.supflu.2011.08.014.

Perrut, M., Perrut, V., 2018. 'Towards Ingredients by Combining Supercritical Fluids with Other Processes. J. Supercrit. Fluids, 30th Year Anniversary Issue of the Journal of Supercritical Fluids 134 (April), 214-219. https://doi.org/10.1016/ j.supflu.2017.11.019.

Perrut, Michel, Perrut, Vincent, 2019. Chapter 7.7 - Supercritical Fluid Applications in the Food Industry. In: Cachon, Rémy, Girardon, Philippe, Voilley, Andrée (Eds.), Gases in Agro-Food Processes. Academic Press, pp. 483-509. https://doi. org/10.1016/B978-0-12-812465-9.00020-7.

Peters, C., Wolff, L., Haase, S., Thien, J., Brands, T., Koß, H.-J., Bardow, A., 2017. Multicomponent Diffusion Coefficients from Microfluidics Using Raman Microspectroscopy. Lab Chip 17 (16), 2768-2776. https://doi.org/10.1039/ C7LC00433H.

Proctor, B.A., Whitney, I., Johnson, J.W., 1967. The Strength of Fused Silica. Proc. R. Soc. Lond. A 297 (1451), 534-557. https://doi.org/10.1098/rspa.1967.0085.

Ren, J., He, S., Ye, C., Chen, G., Sun, C., 2012. The Ozone Mass Transfer Characteristics and Ozonation of Pentachlorophenol in a Novel Microchannel Reactor. Chem. Eng. J. 210 (November), 374-384. https://doi.org/10.1016/j.cej.2012.09.011.

Span, R., Wagner, W., 1996. A New Equation of State for Carbon Dioxide Covering the Fluid Region from the Triple-Point Temperature to $1100 \mathrm{~K}$ at Pressures up to 800 MPa. J. Phys. Chem. Ref. Data 25 (6), 1509-1596. https://doi.org/10.1063/ 1.555991.

Steijn, Volkert van, Kreutzer, Michiel T., Kleijn, Chris R., 2007. $\mu$-PIV Study of the Formation of Segmented Flow in Microfluidic T-Junctions. Chemical Engineering Science, 8th International Conference on Gas-Liquid and GasLiquid-Solid Reactor Engineering, 62(24), 7505-14. https://doi.org/10.1016/j. ces.2007.08.068

Susanti, J.G.M., Winkelman, B.S., Heeres, H.J., Yue, J., 2016. Lactic Acid Extraction and Mass Transfer Characteristics in Slug Flow Capillary Microreactors. Ind. Eng. Chem. Res. 55 (16), 4691-4702. https://doi.org/10.1021/acs.iecr.5b04917.

Tan, J., Lu, Y.C., Xu, J.H., Luo, G.S., 2012. Mass Transfer Characteristic in the Formation Stage of Gas-Liquid Segmented Flow in Microchannel. Chem. Eng. J. 185-186 (March), 314-320. https://doi.org/10.1016/j.cej.2012.01.054.

Temelli, F., 2009. Perspectives on supercritical fluid processing of fats and oils. J. Supercrit. Fluids 47 (3), 583-590 https://linkinghub.elsevier.com/retrieve/pii/ S0896844608003598. https://doi.org/10.1016/j.supflu.2008.10.014.

Tsai, W.-C., Wang, Y., 2019. Progress of Supercritical Fluid Technology in Polymerization and Its Applications in Biomedical Engineering. Prog. Polym. Sci. 98, (November). https://doi.org/10.1016/j.progpolymsci.2019.101161 101161.

Vandu, C.O., Liu, H., Krishna, R., 2005. Mass transfer from Taylor bubbles rising in single capillaries. Chem. Eng. Sci. 60 (22), 6430-6437 https://linkinghub. elsevier.com/retrieve/pii/S0009250905000813. https://doi.org/10.1016/j. ces.2005.01.037.

Yao, C., Dong, Z., Zhao, Y., Chen, G., 2014. An Online Method to Measure Mass Transfer of Slug Flow in a Microchannel. Chem. Eng. Sci. 112 (June), 15-24. https://doi.org/10.1016/j.ces.2014.03.016.

Yao, C., Zhu, K., Liu, Y., Liu, H., Jiao, F., Chen, G., 2017. Intensified CO2 Absorption in a Microchannel Reactor under Elevated Pressures. Chem. Eng. J. 319 (July), 179190. https://doi.org/10.1016/j.cej.2017.03.003.

Yue, J., Chen, G., Yuan, Q., Luo, L., Gonthier, Y., 2007. Hydrodynamics and Mass Transfer Characteristics in Gas-Liquid Flow through a Rectangular Microchannel. Chem. Eng. Sci. 62 (7), 2096-2108. https://doi.org/10.1016/j. ces.2006.12.057.

Yue, J., Luo, L., Gonthier, Y., Chen, G., Yuan, Q., 2009. An Experimental Study of AirWater Taylor Flow and Mass Transfer inside Square Microchannels. Chem. Eng. Sci. 64 (16), 3697-3708. https://doi.org/10.1016/j.ces.2009.05.026.

Zaloha, P., Kristal, J., Jiricny, V., Völkel, N., Xuereb, C., Aubin, J., 2012. Characteristics of Liquid Slugs in Gas-Liquid Taylor Flow in Microchannels. Chem. Eng. Sci. 68 (1), 640-649. https://doi.org/10.1016/j.ces.2011.10.036.

Zhang, P., Yao, C., Ma, H., Jin, N., Zhang, X., Lü, H., Zhao, Y., 2018. Dynamic Changes in Gas-Liquid Mass Transfer during Taylor Flow in Long Serpentine Square Microchannels. Chem. Eng. Sci. 182 (June), 17-27. https://doi.org/10.1016/j. ces.2018.02.018. 